\title{
Performance Analysis of Autonomous DFIM Based Wind Energy Generation System
}

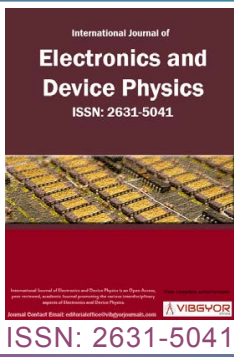

\section{Venktesh Mishra', Premnath Gupta ${ }^{1}$ and Rishabh Dev Shukla ${ }^{2^{*}}$}

${ }^{1}$ Department of Electronics and Communication Engineering, J.K. Institute of Applied Physics and Technology, University of Allahabad, India

${ }^{2}$ Department of Electrical Engineering, Budge Budge Institute of Technology, India

\begin{abstract}
This paper presents the performance analysis of an autonomous DFIG based wind energy generation system under the different possible conditions. A variable speed-constant frequency wind energy generation system, supplying an isolated load, is designed via wound rotor induction machine and back-to-back coupled power electronics converters, connected in between stator and rotor of machine. Indirect stator flux-oriented control technique is used towards rotor side converter for regulating the voltage and frequency at the stator terminal. In order to provide the load harmonic compensation, shunt active power filtering function is embedded in the control of the stator/load side converter control. Hysteresis controllers are used for providing control pulses for both the converters. These control pulses achieved through generated error signals, by comparing the actual and reference rotor current. The simulation of 2 MVA wind energy generation systems is done through wound rotor induction machine prototype in MATLAB/Simulink. The simulation results obtained from the 2 MVA systems are observed and analysed in this paper.
\end{abstract}

\section{Keywords}

DFIG, Stator side converter, Rotor side converter, Hysteresis current controller, Variable speedconstant frequency operation

\section{Introduction}

From the last few decades wind energy plays a significant role as a source of renewable energy over the world because of wind energy is easily available in nature and play an important role in the economic growth $[1,2]$. In the older days, squirrelcage induction generators are used for wind energy generation system through utility grid. It is running at constant speed to draw reactive power from the grid [3]. A constant speed wind energy system contains a number of gearbox stages, operates in a narrow range of synchronous speed. Now-a-days the wind turbine technology has moved towards its variable speed operation which provides the higher energy output through maximum power point tracking and less stress on the mechanical parts of the system. Double Fed Induction Machine (DFIM) is

*Corresponding author: Rishabh Dev Shukla, Department of Electrical Engineering, Budge Budge Institute of Technology, West Bengal, India

Accepted: April 25, 2019; Published: April 27, 2019

Copyright: (C) 2019 Mishra V, et al. This is an open-access article distributed under the terms of the Creative Commons Attribution License, which permits unrestricted use, distribution, and reproduction in any medium, provided the original author and source are credited.

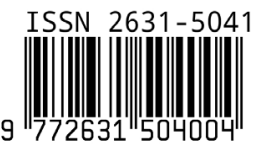

Mishra et al. Int J Electron Device Phys 2019, 3:005 
very well-known concept under the variable speed wind turbine technology [4]. DFIM based wind energy generation topology is consists of a wound rotor induction machine, a wind turbine, and power converters with common capacitive link connected between rotor and stator [5]. DFIM topology has lots of advantages such as wide operation range of speed about $+30 \%$ to $-30 \%$ of synchronous speed, fractionally rated converter which reduces the cost of the system, decoupled control of active and reactive powers to and from the utility grid, lesser losses and higher efficiency of the overall system. Sufficiently large number of research articles has been found on DFIM based wind energy system in literature [6-10]. These studies on DFIM based wind energy system were based on connection with the conventional utility grid. Different control schemes and converter topologies have been developed for the conventional grid connected [10-12]. The major drawback of this conventional DFIM topology is the requirement of the connection with stiff utility grid. The conventional grid connected DFIM systems are useless under the condition of utility or main grid outage $[13,14]$. Also, these systems are not being used for the isolated or remote areas because of absence of utility grid [15].

Some researcher has tried to make the conventional DFIM based system utilizable in isolated or remote areas even in the absence of utility grid [15-19]. In these isolated or autonomous DFIM based systems, the main issue, which must be addressed, is the regulation of stator/load voltage and frequency control [20]. A direct voltage control method was proposed in [15-19] which are dependent on the load characteristics. An instantaneous direct voltage and frequency control technique was presented, applicable for both balance and unbalance loads, in [21] which is just an improvement of the direct voltage control. In [22], indirect control technique was presented without considering the effect of non-linear loading.

So, considering the above issue, this paper presents a complete performance analysis on autonomous DFIM based system. The information/analysis presented in this paper is very helpful for researchers working in same area to understand the issues, functioning and control in regard to autonomous DFIM based system. The stator flux-oriented control method is presented to control the rotor side power converter which is responsible for the regulation of stator/load side voltage and frequency. An improvement is proposed for the stator side power converter which is the addition of filtering function to control of the side converter. The stator side power converter is working as the shunt active filter which is responsible to give the compensation of the load harmonics. The structure of the whole paper is as follows: Section 2 provides fundamental concepts of wind turbine and overview of autonomous DFIM based wind energy generation system, selection of filter capacitor. In section 3 discusses the control technique of rotor side converter to regulate the voltage and frequency at the stator terminal and section 4 discusses the load/stator side converter control for load harmonics compensation. Section 5 contains all simulation results and discussions.

\section{Methodology of Autonomous Wind Energy Generation System}

The generated power through wind turbines can be expressed as [23].

$$
P=0.5 \rho \pi R^{2} V^{3} C_{P}(\lambda, \beta)
$$

The relationship between delivered and theoretical wind power can be given by $c_{p}$ curve of wind turbine. It is a function of tip speed ratio $\lambda$ and blade pitch angle $\beta$. The pitch-controlled mechanism is specified for wind turbine given as $\lambda$ $=R \omega / \mathrm{V}$, where $\omega_{r}$ is the rotational speed of wind turbine. Active pitch angle control is preferred for higher wind speed; by changing the rotor blades angle from actual wind direction the aerodynamic power can be reduced. The aerodynamic power captured by turning the rotor blades is the cosine function of the given pitch angle. For low to medium speed of wind speed pitch angle is supposed to zero. A number of gearboxes are used to produce high torque so that wind energy system can produce clean electricity under variable wind speed. In autonomous wind energy generation system using doubly fed induction generator, the stator is attached with an isolated load in spite of grid. Figure 1 shows the basic building block of autonomous wind energy generation system using doubly fed induction generator with a remote load.

In case of synchronously rotating reference frame the fundamental equation for representing the wound rotor induction generation system is given as [18]: 


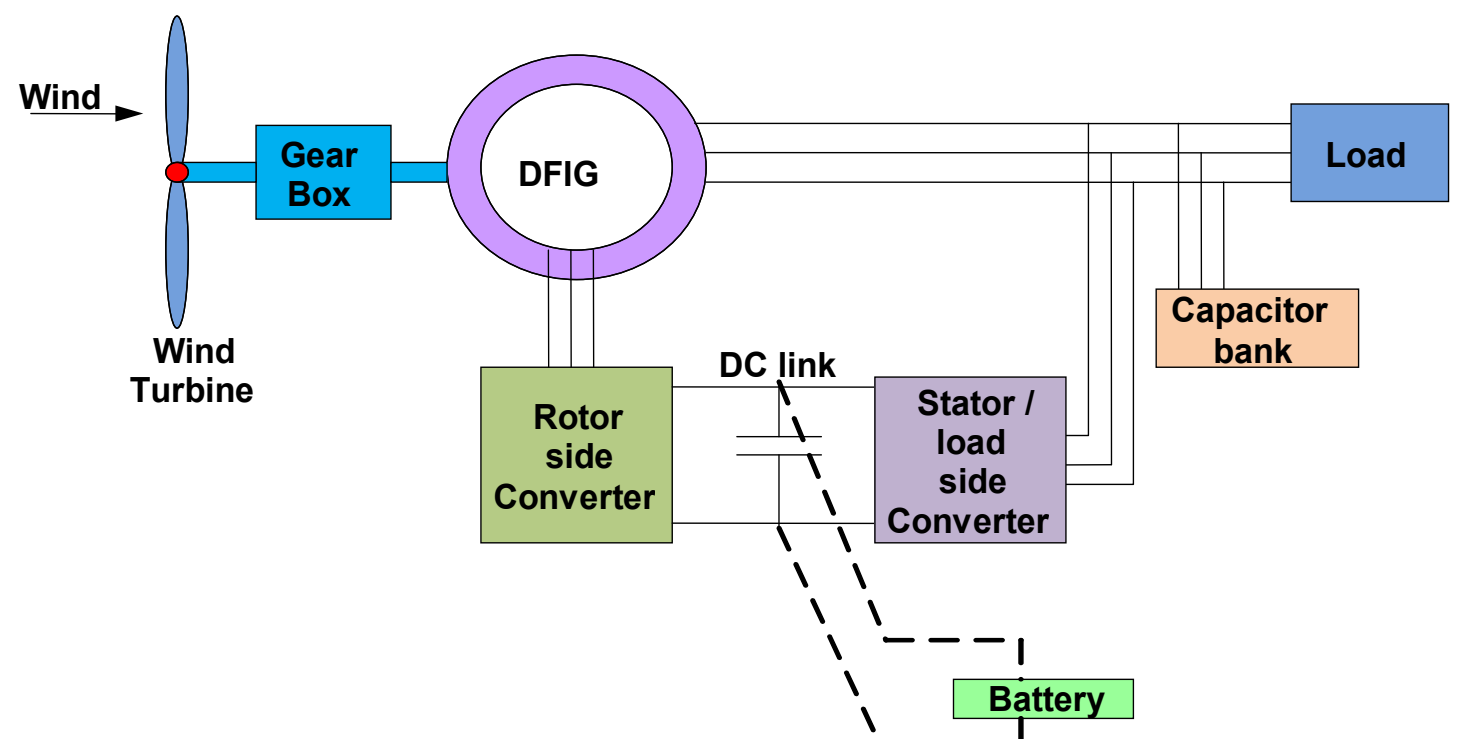

Figure 1: Autonomous wind energy generation system supported by a battery.

$$
\begin{aligned}
& v_{s d}=R_{s} i_{s d}+\frac{d \lambda_{s d}}{d t}-\omega_{s} \lambda_{s q} \\
& v_{s q}=R_{s} i_{s q}+\frac{d \lambda_{s q}}{d t}-\omega_{s} \lambda_{s d} \\
& v_{r d}=R_{r} i_{r d}+\frac{d \lambda_{r d}}{d t}-\left(\omega_{s}-\omega_{r}\right) \lambda_{r q} \\
& v_{r}=R_{r} i_{r q}+\frac{d \lambda_{r q}}{d t}+\left(\omega_{s}-\omega_{r}\right) \lambda_{r d} \\
& \lambda_{s d}=L_{s} i_{s d}+L_{m} i_{r d} \\
& \lambda_{s q}=L_{s} i_{s q}+L_{m} i_{r q} \\
& \lambda_{r d}=L_{r} i_{r d}+L_{m} i_{s d} \\
& \lambda_{s q}=L_{r} i_{r q}+L_{m} i_{s q} \\
& T_{e}=3 \frac{p}{2} L_{m}\left(i_{s q} i_{r d}-i_{s d} i_{r q}\right)
\end{aligned}
$$

Here suffix ' $s$ ' and ' $r$ ' are representation of the stator and rotor quantities, similarly suffix ' $d$ ' and suffix ' $q$ ' denote the direct $d$-axis quantities and quadrature q-axis quantities, rest all used in normal manner. The mathematical modeling of autonomous wind energy generation system using doubly fed induction generator follows the same equations which are used in the grid connected system [eq $\left.{ }^{n}(2)-(10)\right]$. In case of autonomous wind energy generation system using doubly fed induction generator system, grid does not provide the stator voltage. Stator voltage obtained by excitation of machine loaded towards stator side. In case of a resistive load the stator voltage is given in eq $^{\mathrm{n}}(11)$ as

$$
v_{S}=-R_{0} i_{S}
$$

It works as a current source when rotor is fed from VSI, controlled by a current thus the equations (3) \& (5) can be neglected. In case of a resistive load after ignoring the stator resistance by considering equation (2) \& (4), the dependency of the rotor current on the stator voltage expressed in dq frame [24] as eq $^{\mathrm{n}}(12)$ :

$$
v_{s}=\frac{R_{o} L_{m}}{Z_{s}} \frac{d i_{r}}{d t}+j\left(\frac{\omega_{s} R_{o} L_{m}}{Z_{s}}\right) i_{r}-\frac{L_{s}}{Z_{s}} \frac{d v_{s}}{d t}
$$

Here $R_{o}$ represent load resistance. After neglecting the stator resistance, stator side impedance can be expressed as $Z_{s}=R_{o}+j \omega_{s} L_{s}$. In case of an unloaded system stator voltage can be expressed as;

$$
v_{s}=L_{m} \frac{d i_{r}}{d t}+j \omega_{s} L_{m} i_{r}
$$

In frequency loop of PWM, the deviation of stator voltage occurs due to generated rotor current ripples. An extra inductor $L_{r_{\text {_add }}}$ is connected in series with rotor leakage inductance. Generated ripples in rotor current can be determined using $\mathrm{eq}^{\mathrm{n}}(2)$ and (4), as shown in eq ${ }^{\mathrm{n}}(14)$;

$$
\frac{d i_{r}}{d t}=\frac{1}{L_{m}+L_{r \sigma}+L_{r_{-} a d d}}\left[v_{r}-R_{r} i_{r}-L_{m} \frac{d i_{r}}{d t}-j\left(\omega_{s}-p_{b} \omega_{s}\right) L_{m} i_{s}\right.
$$


Under no load condition, the quality of stator voltage is not enough good using inductive filters. It is a major drawback autonomous wind energy generation system using doubly fed induction generator, for producing extremely good quality of voltage independent on load. Filtering capacitors are attached on stator side to overcome such type of problems. For current formation inductors are required in an autonomous wind energy generation system using doubly fed induction generator because machine itself having high inductance. Filtering capacitors at the stator side are used to generate high quality voltage. During selection of capacitor one thing keeps in mind that the capacitor $C_{f}$ does not completely compensated through the reactive power of magnetization. However, the generated frequency depends on the mechanical speed to provide the reference frequency $(50 \mathrm{~Hz})$ at the stator terminal given as $[13,20,24]$.

$$
C_{f}<\frac{1}{4 \Pi^{2} f_{m}^{2} L_{m}}
$$

Resonant frequency $f_{r}$ of the output filter $\mathrm{L}_{\mathrm{rso}} \mathrm{C}_{f^{\prime}}$ whose value is to be significantly small as compare to the switching frequency, the value of capacitor is given as:

$$
C_{f}=\frac{1}{4 \Pi^{2} f_{r}^{2} \sigma L_{m}}
$$

$$
\text { Where } \sigma=\left(1-\frac{L_{m}^{2}}{L_{s}+L_{m}}\right)
$$

\section{Rotor End Power Converter Control}

Under different operating condition the voltage and frequency control at the stator terminal is main task of the rotor side converter. Field oriented controlled technique is applied for the regulation of the rotor side converter, i.e. stator flux-oriented reference frame is designed for the rotor side controller. Filter capacitors are connected between stator and rotor side converter providing stator magnetizing current. The $d$-axis of the reference frame is aligning towards stator flux vector using eq $^{n}(7)$; we get in eqn $(17)[22,25,26]$.

$$
i_{r q}=-\frac{L_{s}}{L_{m}} i_{s q}
$$

Using the eq ${ }^{\mathrm{n}} s(2)-(10)$, calculating for $\mathrm{i}_{\mathrm{m}}$ and eliminating $i_{s d}$ and $i_{s q}$, with $\lambda_{q s}=0$, we get as given in eq ${ }^{\mathrm{n}} \mathrm{s}(18)$.

$$
\begin{aligned}
& \tau_{m} \frac{d i_{m}}{d t}+i_{m}=i_{r d}+\frac{1+\sigma_{s}}{R_{s}} v_{s d} \\
& T_{e}=-3 \frac{p}{2} \frac{L_{m}^{2}}{L_{s}} i_{m} i_{r q}
\end{aligned}
$$

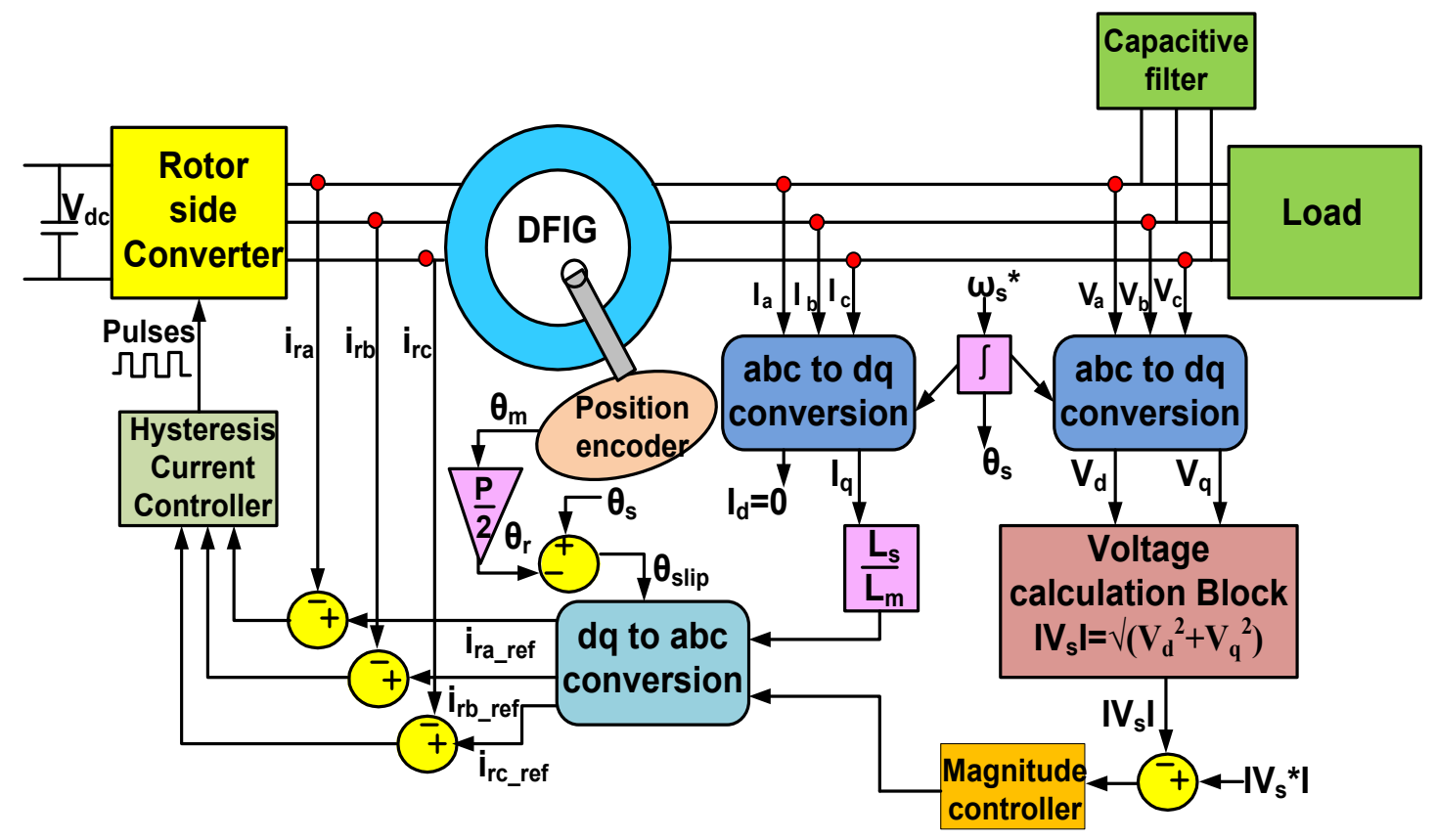

Figure 2: Control technique for rotor side converter. 


$$
\text { Where } \tau_{m}=\frac{L_{s}}{R_{s}}
$$

In case of constant flux operation, the last two terms of $e^{n}(18)$ are set to be zero and the value of $v_{d s}$ is very less, from eqn (18) it is clear that the current $i_{m}$ controlled through $i_{d r}$. Thus, rotor current can be controlled through given expression:

$$
i_{q r}^{*}=-\frac{L_{s}}{L_{m}} i_{q s}
$$

It forces for the rotation of reference frame with vector position of stator flux. Thus, stator voltage of machine is controlled by regulating, the $i_{r d}$ direct axis rotor current. The $i_{r d}^{*}$ reference direct axis rotor current is calculated by the error signal, obtained by the subtracting the desired or reference stator/output voltage and measured stator terminal voltage as given in $\mathrm{eq}^{\mathrm{n}}(20)$, through magnitude controller (i.e. proportional integral controller) as given in Figure 2.

$$
\left|V_{s}\right|=\sqrt{v_{s d}^{2}+v_{s q}^{2}}
$$

Where $v_{s d}$ and $v_{s q}$ are given as in eq ${ }^{\mathrm{n}}(21)$ $v_{s d}=\frac{2}{3}\left(v_{s a} \cos \cos \left(\omega_{S} t\right)+v_{s b} \cos \cos \left(\omega_{S} t-\frac{2}{3} \pi\right)+v_{s c} \cos \cos \left(\omega_{S} t+\frac{2}{3} \pi\right)\right)$

$v_{s q}=\frac{2}{3}\left(v_{s a} \sin \sin \left(\omega_{s} t\right)+v_{s b} \sin \sin \left(\omega_{s} t-\frac{2}{3} \pi\right)+v_{s c} \sin \sin \left(\omega_{s} t+\frac{2}{3} \pi\right)\right)$ (21)

Inverse park transformation method are applicable to convert the $i_{r d}^{*}$ and $i_{r q}^{*}$ reference rotor current components into 3-phase reference rotor currents $i_{r a}{ }^{*}, i_{r b}{ }^{*}, i_{r c}{ }^{*}$ using the slip angle, $\theta_{s i p}=\theta_{s}-\theta_{r}=\int \omega_{s} d t-\theta_{r}$. When the reference rotor phase currents are compared with the measured rotor phase currents, then induced pulses because of error signals are used to perform the turn ON and turn OFF operation of the hysteresis controller present towards the rotor side converter.

\section{Stator/load End Power Converter Control}

The conventional control scheme for stator/ load-end converter, given in [22], is only valid for linear loads. A modified control method for stator/ load side converter is given for compensation of load harmonic generated due to non-linear loads. It is based upon the shunt active power filtering function and uses the load current instantaneous active and reactive components $[27,28]$. The sta-

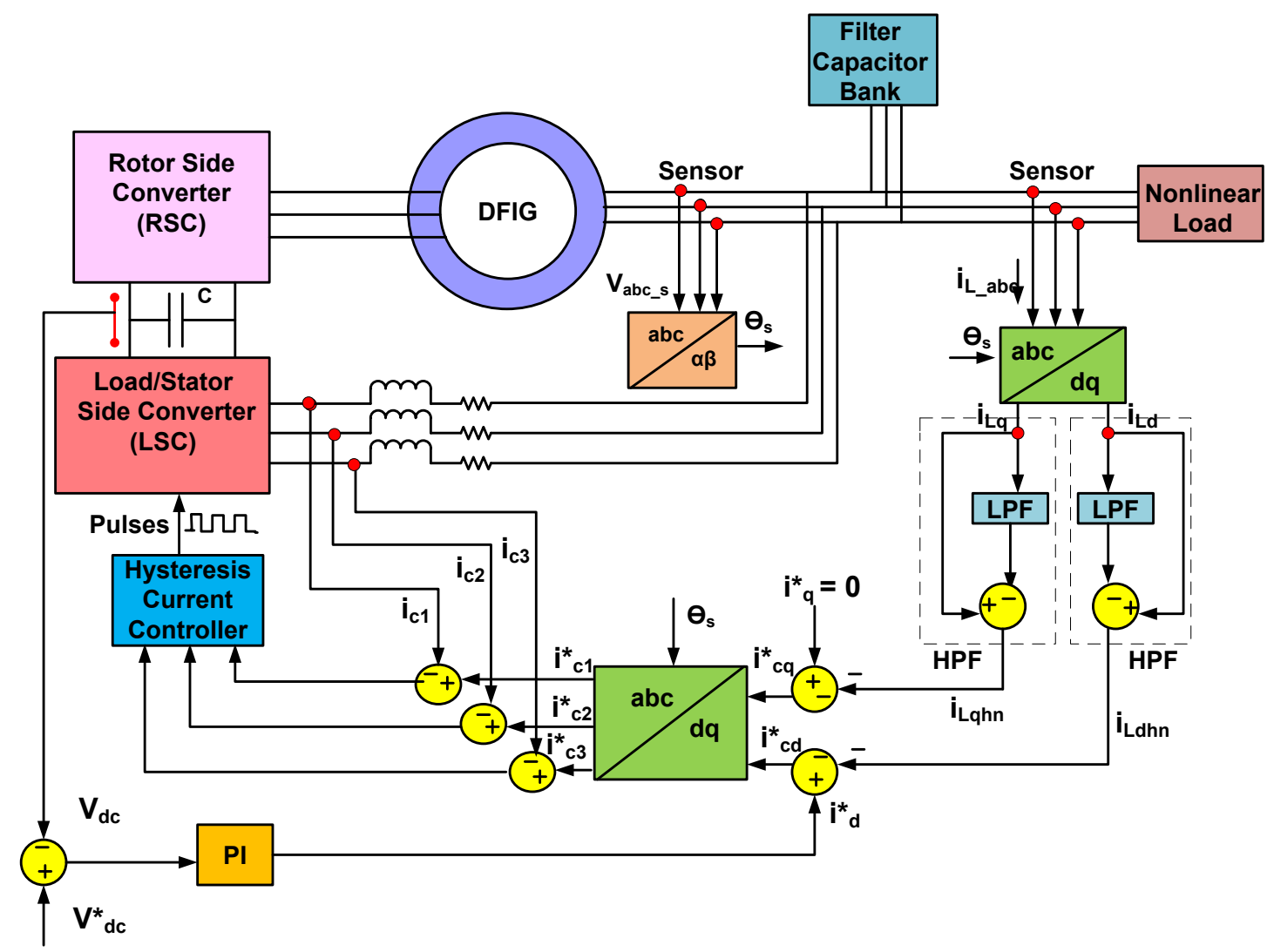

Figure 3: Proposed control technique for stator side converter. 
tor/load side converter is used to maintain the dc link voltage constant regardless the direction of rotor power flow. The dc link energy storage system provides the system stability by adjusting frequency and voltage close to their reference value, when frequency and voltage deviates because of wind speed variation. When generated power is more than nonlinear load demand, then controller absorbed extra energy into the storage system up to the maximum charging limit. When load demand is higher than production, the storage system provides the additional energy. The shunt active power filter theory is added in the basic control method of the stator/load side converter to improve the performance of the controller under the non-linear loads condition.

An improved scheme by applying described principle of shunt active power filters, for the stator-end converter is proposed in Figure 3. Thus, in this study the actual function of stator-end converter is to provide for load harmonic compensation and reactive power requirement of doubly fed induction generator.

\section{Results and Discussion}

In the preceding sections both load side converter and rotor side converter are already discusses. The simulation model for variable speed autonomous wind energy generation system using doubly fed induction machine is designed in the MATLAB/ Simulink. The discussion of results, recorded at different condition, is presented in this section. Load side converter are used for compensation of generated load harmonics and provide the reactive power requirement at different load condition while the rotor side converter is used for constant voltage-constant frequency at load end. Required parameters of simulation and rating of power electronics converters are listed in Table 1 [29]. Wind speed is regulated to produce required power for different load condition. To provide the initial magnetization of the system, a dc battery source is needed for time duration of 0 to $0.1 \mathrm{sec}$. Required reference stator voltage for simulation is $690 \mathrm{Vrms}$ line-to-line (or $976 \mathrm{~V} \_$peak) i.e. $398.38 \mathrm{Vrms}$ lineto-ground (or $563.38 \mathrm{Vph}$,peak). After Simulation various results are obtain who shows that the generated stator voltage follows the reference value and remain at the specified value (i.e. 976V_peak or 563.38 Vph_peak) and the frequency is equal to $50 \mathrm{~Hz}$ in both cases. Under the different operating
Table 1: Simulation data [29].

\begin{tabular}{|l|l|}
\hline DFIG Parameter & Value \\
\hline Nominal rated power & $2 \mathrm{MVA}$ \\
\hline $\begin{array}{l}\text { Rated Line-to-line stator } \\
\text { voltage (Vrms) }\end{array}$ & $690 \mathrm{~V}$ \\
\hline $\begin{array}{l}\text { Rated Line-to-line rotor } \\
\text { voltage (Vrms) }\end{array}$ & $2070 \mathrm{~V}$ \\
\hline Stator and rotor connection & Star and Star \\
\hline Nominal frequency & $50 \mathrm{~Hz}$ \\
\hline $\begin{array}{l}\text { Stator resistance \& leakage } \\
\text { inductance }\end{array}$ & $2.6 \mathrm{~m} \Omega$ \& $0.087 \mathrm{mH}$ \\
\hline $\begin{array}{l}\text { Rotor resistance \& leakage } \\
\text { inductance }\end{array}$ & $26.1 \mathrm{~m} \Omega$ \& 0.783 mH \\
\hline Magnetization inductance & $2.5 \mathrm{mH}$ \\
\hline No. of pole pair & 2 \\
\hline Matching transformer rating & $1 \mathrm{MVA}, 690 / 2070 \mathrm{~V}_{\mathrm{rms}}$ \\
\hline Sampling time & $10 \mu \mathrm{sec}$ \\
\hline IGBT switch (6 no.) & $3300 \mathrm{~V}, 1200 \mathrm{~A}$ \\
\hline Power diode (6 no.) & $2000_{\mathrm{rms}} 1000 \mathrm{~A}$ \\
\hline
\end{tabular}

condition shows the constant load voltage and variable current, variation in active and reactive power and also change in generator torque and speed depend on the operating load condition shown by simulation. The circular shape of stator flux in $d-q$ plane shows that output current is sinusoidal in nature. In the simulation some variations occur in the $\mathrm{d}$-q plane depending on the load condition.

\section{Consider the effect of load switching at constant wind speed}

Effect of load switching on the performance of wind energy generation system under constant wind speed (at $11 \mathrm{~m} / \mathrm{s}$ ) is studies in this case. Suppose a fixed load of $200 \mathrm{~kW} \& 10 \mathrm{kVAr}$ is connected throughout the simulation time i.e. 0 to $6 \mathrm{sec}$. Apart from it two additional loads of the same size (i.e. $200 \mathrm{~kW} \& 10 \mathrm{kVAr}$ ) are connected for the duration of 1.5 to $4.5 \mathrm{sec}$ and 3 to $4.5 \mathrm{sec}$ respectively. Simulation study is performed to observe the effect of this load switching. Various simulated parameters are recorded and are presented in Figure 4, Figure 5, Figure 6, Figure 7, Figure 8, Figure 9, Figure 10 and Figure 11.

Figure 4 shows that load/stator voltage $\left(v_{a b c}\right)$ remains fixed on its reference value i.e. 398.38 Vrms (or 563.39 Vpeak) phase-to-ground for different (varying) loads but as per the variation in the 

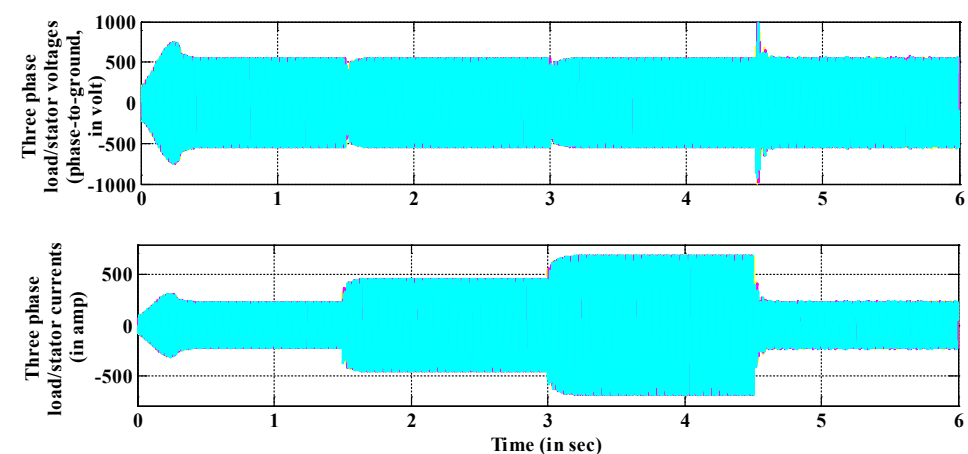

a)
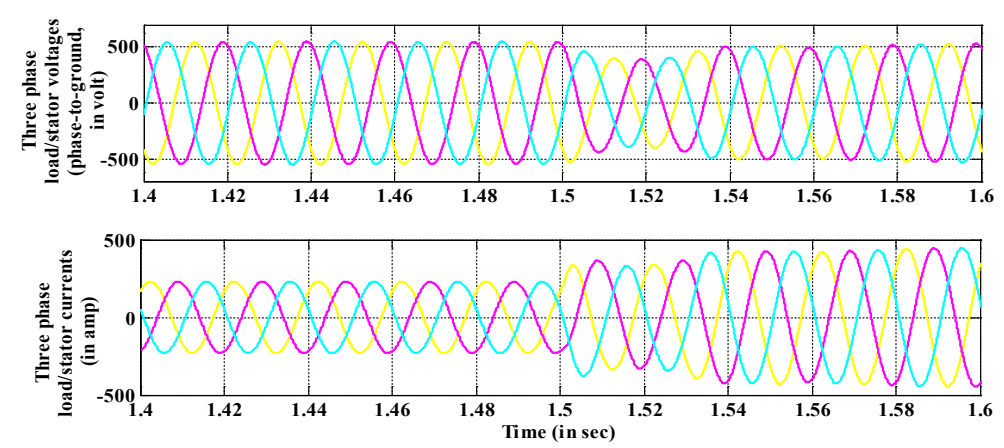

b)
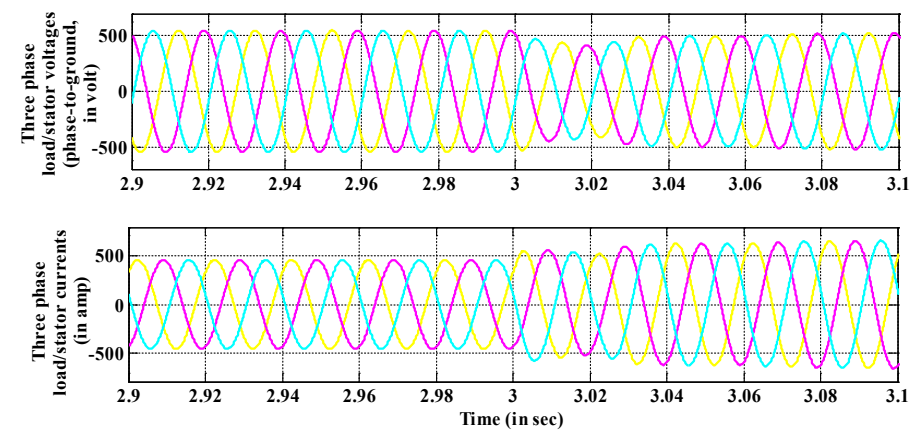

c)
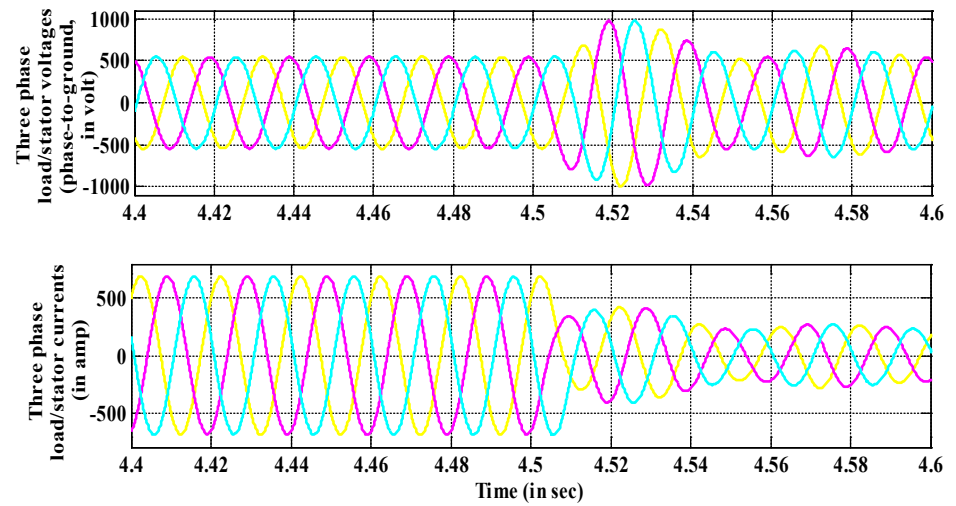

d)

Figure 4: a) Three phase stator/load voltages [phase-to-ground, in Volt] and currents [in Amp]; b) Enlarged time (1.4 to $1.6 \mathrm{sec}$ ) views of Figure 4a; c) Enlarged time (2.9 to $3.1 \mathrm{sec}$ ) views of Figure 4a; d) Enlarged time (4.4 to $4.6 \mathrm{sec}$ ) views of Figure 4a. 


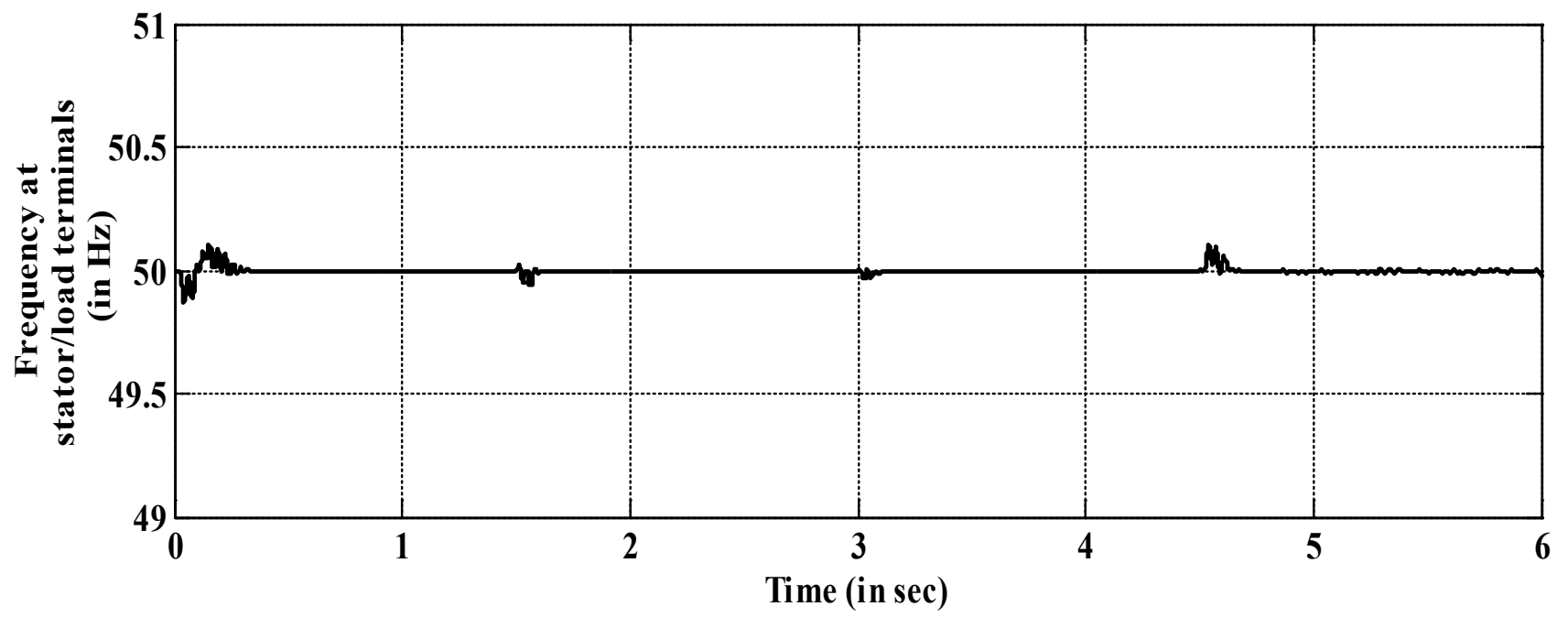

Figure 5: Frequency at load/stator terminals (in $\mathrm{Hz}$ ).

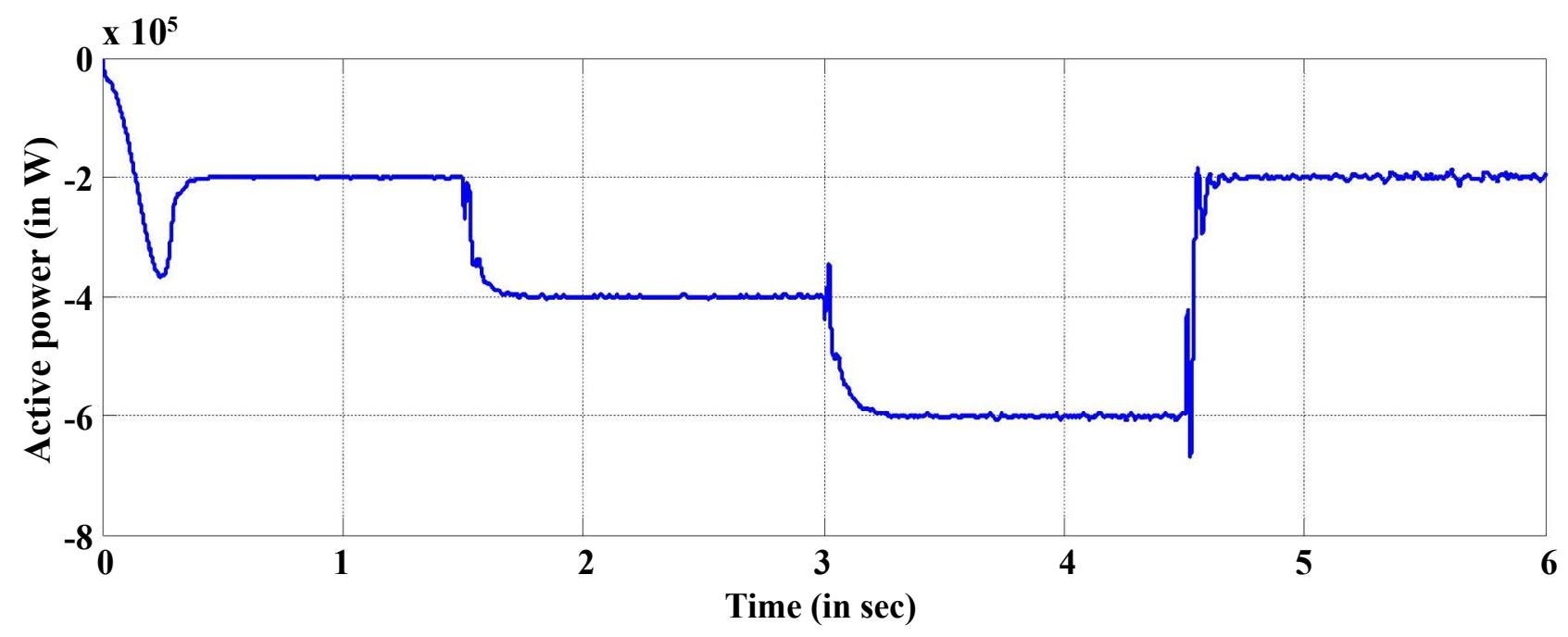

Figure 6: Active power (in Watt).

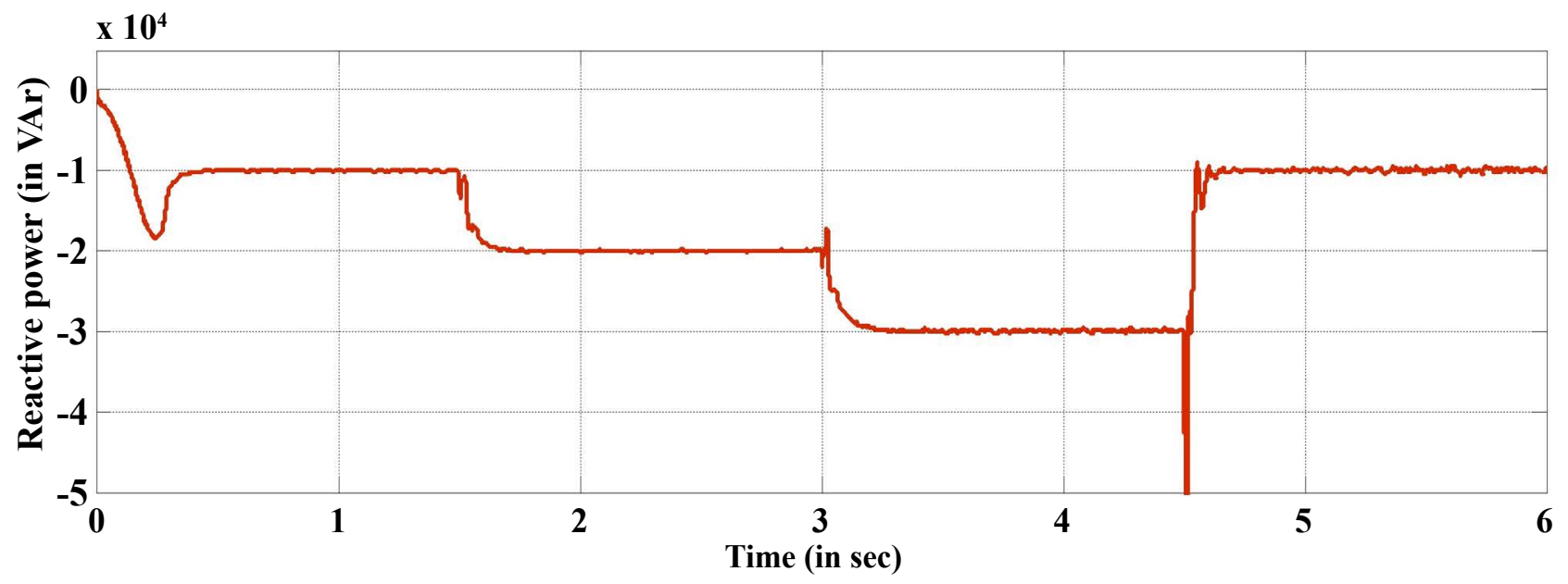

Figure 7: Reactive power (in Volt-Amp-reactive). 


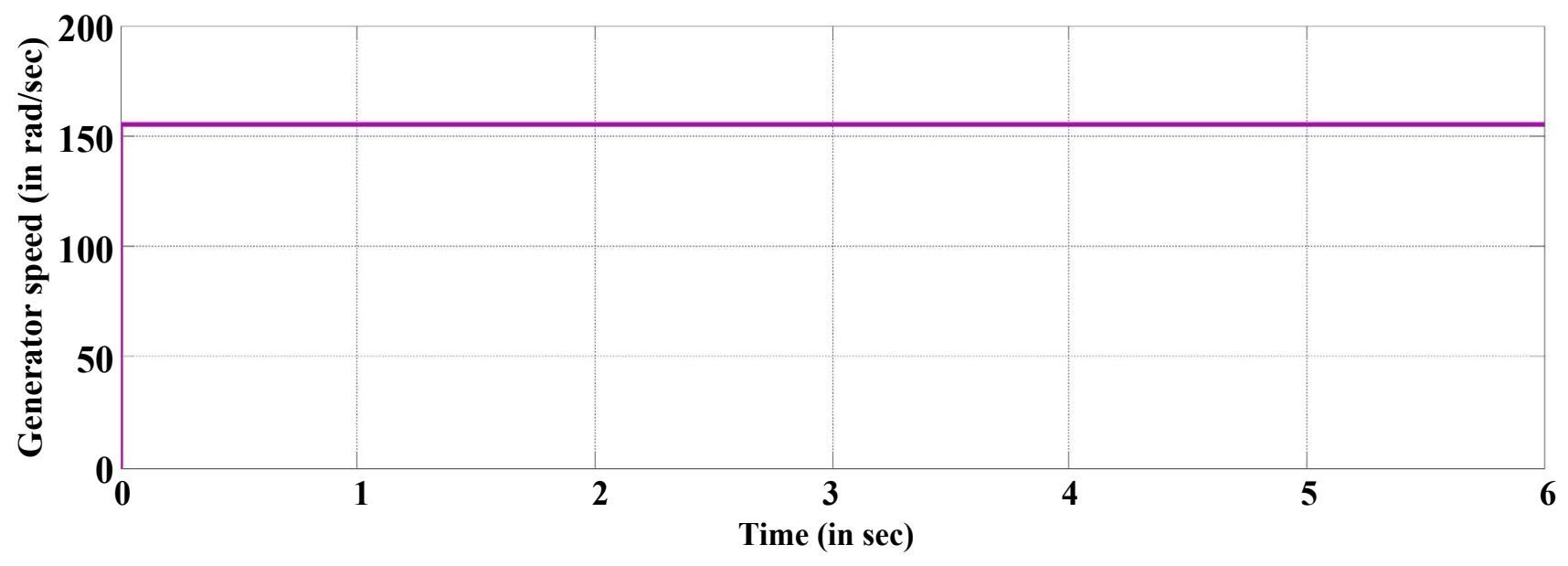

Figure 8: Speed of the generator given in rad/sec.

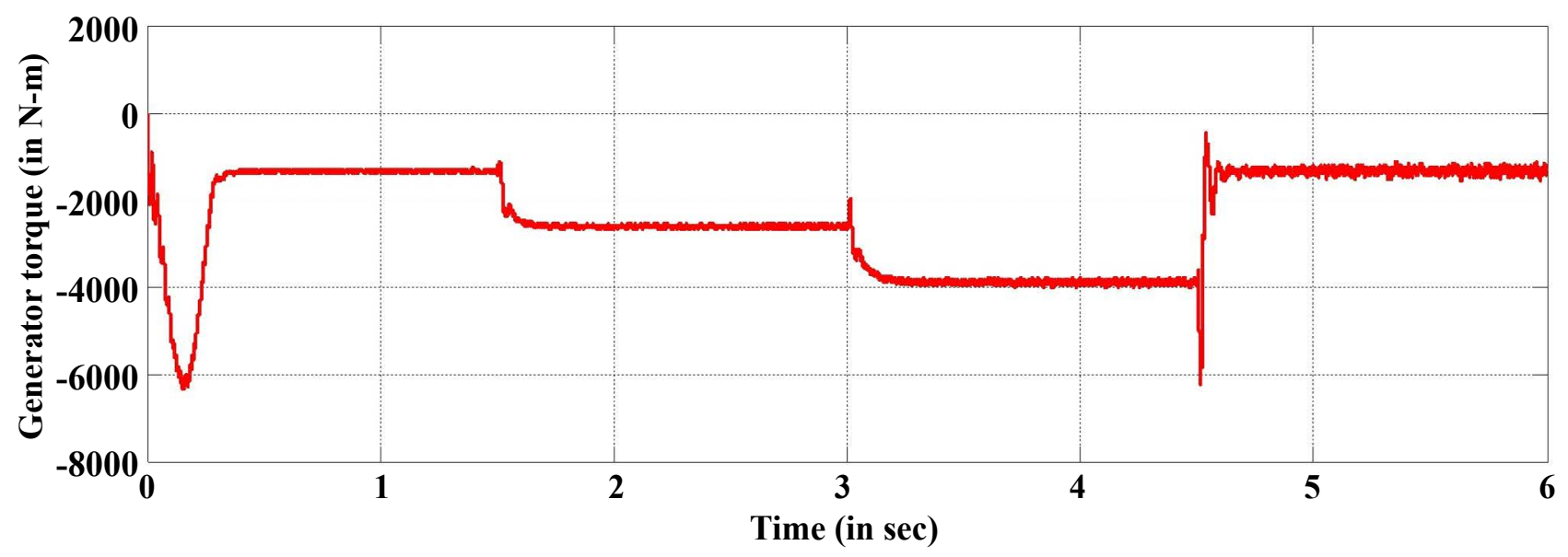

Figure 9: Torque of the generator given in $\mathrm{Nm}$.

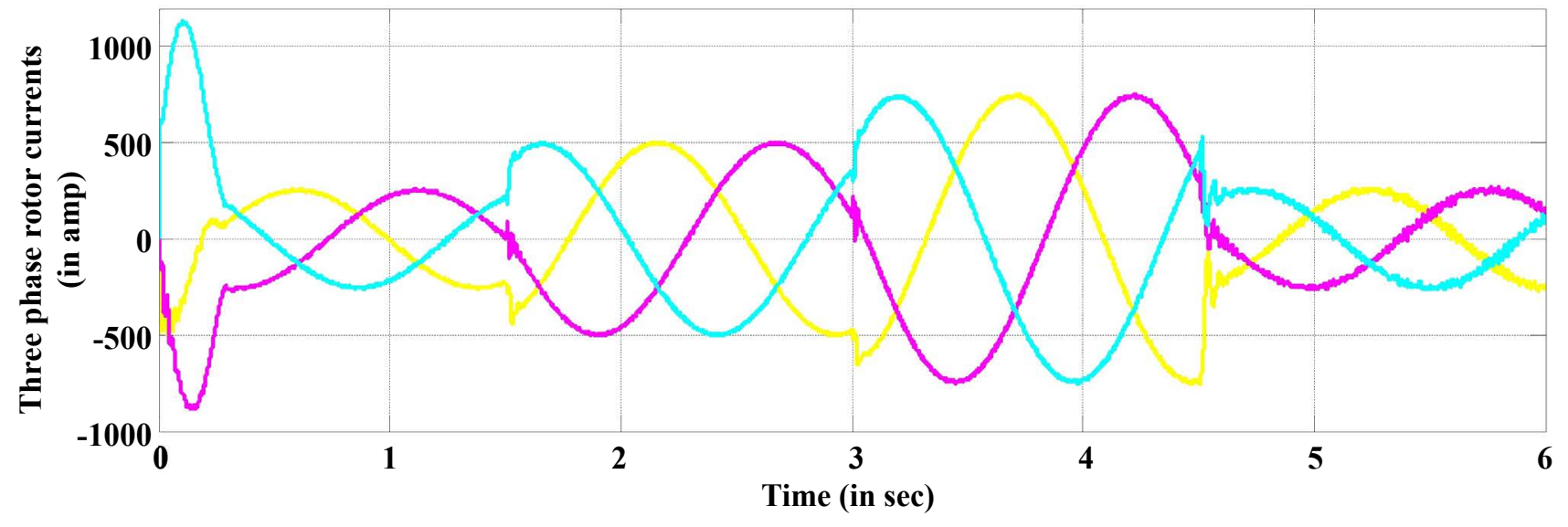

Figure 10: Rotor currents in all three phase given in Amp.

load, the magnitude of load current is changing Fig- larged views of Figure $4 \mathrm{a}$ at load switching points ure 4b, Figure 4c and Figure 4d represent the en- i.e. around $1.5 \mathrm{sec}, 3 \mathrm{sec}$ and $4.5 \mathrm{sec}$. respective- 


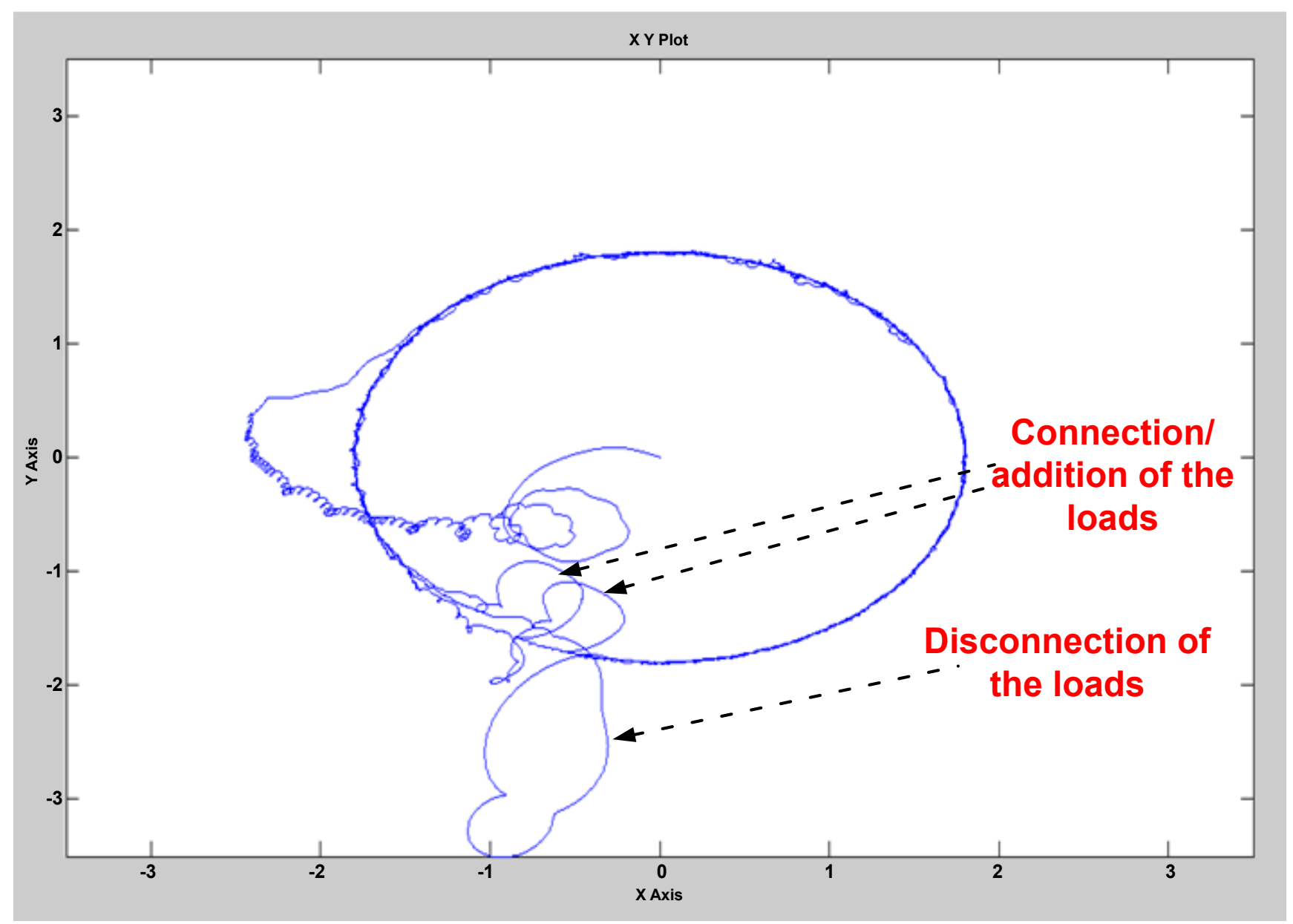

Figure 11: Stator flux in d-q plan under the variable loading.

ly. Figure 5 represents stator frequency, which is constant at reference frequency $(50 \mathrm{~Hz})$, a little bit frequency variations occur at load switching condition. The active power represented in Figure 6 contains value up to $0.2 \mathrm{MW}$ at $1.5 \mathrm{sec}$ (i.e. $200 \mathrm{~kW}$ ). The power delivering capacity of the generator represented by negative sign (shows induction motor working as generator), which is applicable for both active and reactive power. For a time duration of 1.5 to $4.5 \mathrm{sec}$ another load is switched ON, value of active power is changed to $0.4 \mathrm{MW}$ (i.e. $400 \mathrm{~kW}$ ) from $0.2 \mathrm{MW}$ (i.e. $200 \mathrm{~kW}$ ). If one more load is also connected for the time duration of 3 to $4.5 \mathrm{sec}$, the value of active power is again changed to $0.6 \mathrm{MW}$ (i.e. $600 \mathrm{~kW}$ ) from $0.4 \mathrm{MW}$ (i.e. $400 \mathrm{~kW}$ ). After the time duration of $4.5 \mathrm{sec}$, these two additional loads are removed then again active power is minimized and reached to its actual value i.e. $0.2 \mathrm{MW}$ (i.e. 200 $\mathrm{kW})$, and reactive power variation shown in Figure 7. The reactive power is equal to $10 \mathrm{kVAr}$ up to 1.5 $\mathrm{sec} ; 20 \mathrm{kVAr}$ for the period 1.5 to $3 \mathrm{sec}$; and 30 kVAr for the period 3 to $4.5 \mathrm{sec}$. At $4.5 \mathrm{sec}$, when additional loads are removed, the reactive power reduces to its original value $10 \mathrm{kVAr}$. The generated speed and torque are shown in Figure 8 and Figure 9 respectively. In case of fixed wind speed operation, the generator speed is also fixed but under variation of load condition value of torque also varied. When the machine is working in generating mode and responds according to the torque provided by the wind turbine, generator torque represented by negative sign. Figure 10 represents rotor currents variation due to load switching operation. The variation of stator flux shown in dq reference plane represented in Figure 11. The generated stator voltage is sinusoidal represented by the circular shape. Some disturbances in the plot are due to the variation in load.

\section{Consider the effect of nonlinear load and constant wind speed}

The performance of wind energy system can be observed under constant wind speed for constant nonlinear load. Suppose a non-linear load of 1000 

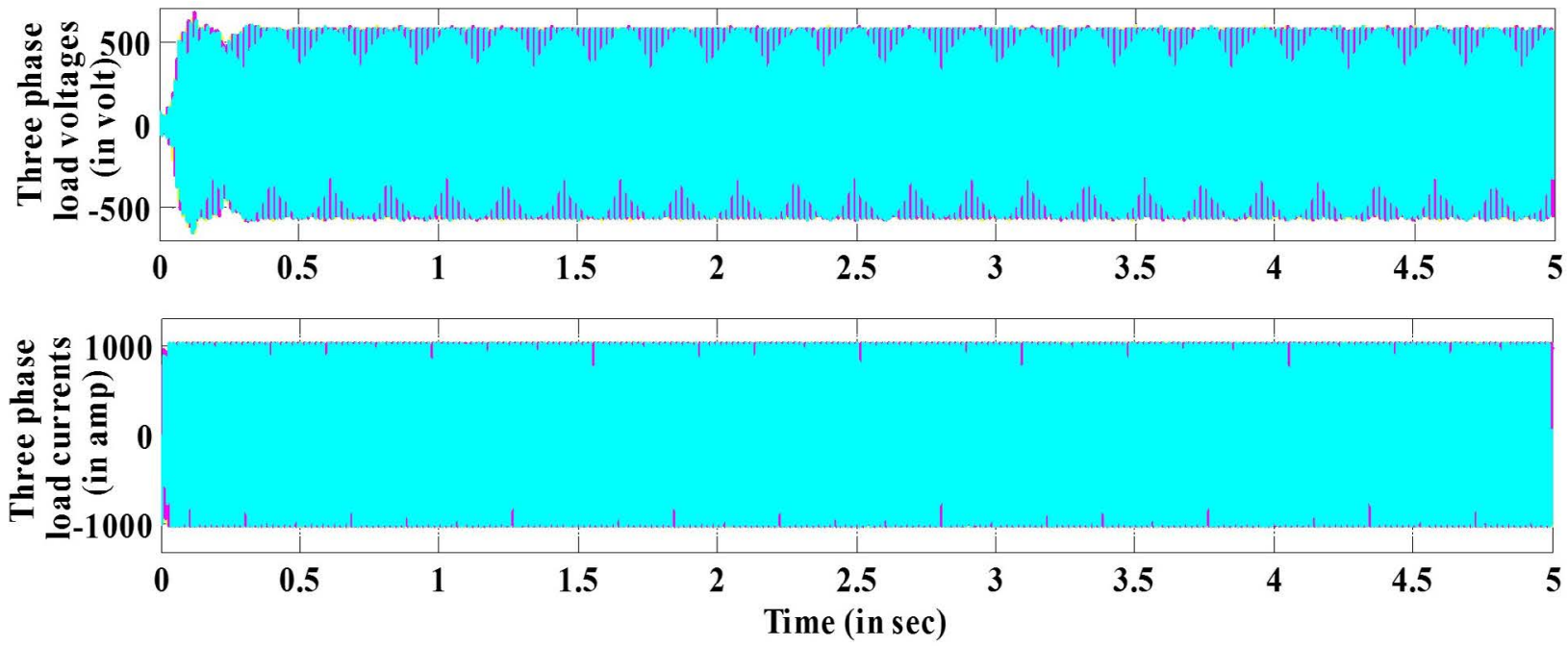

a)
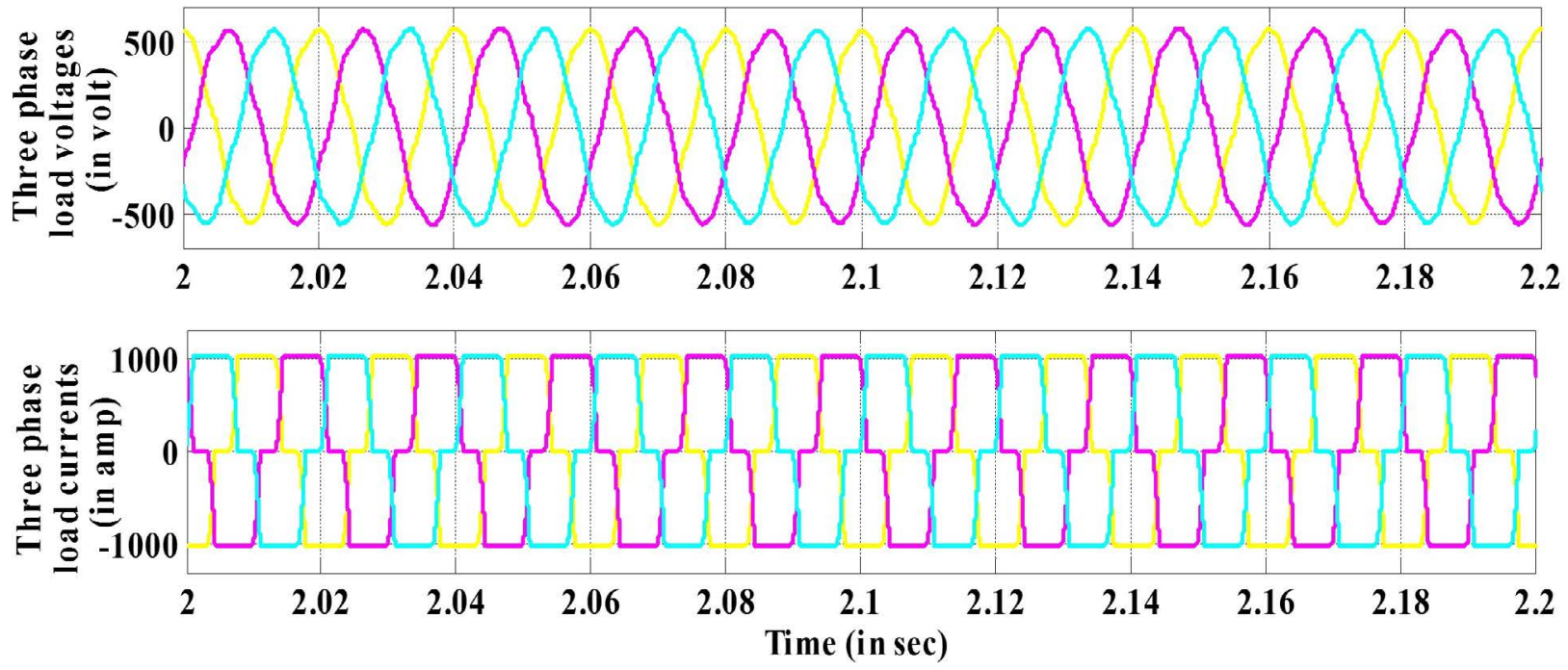

b)

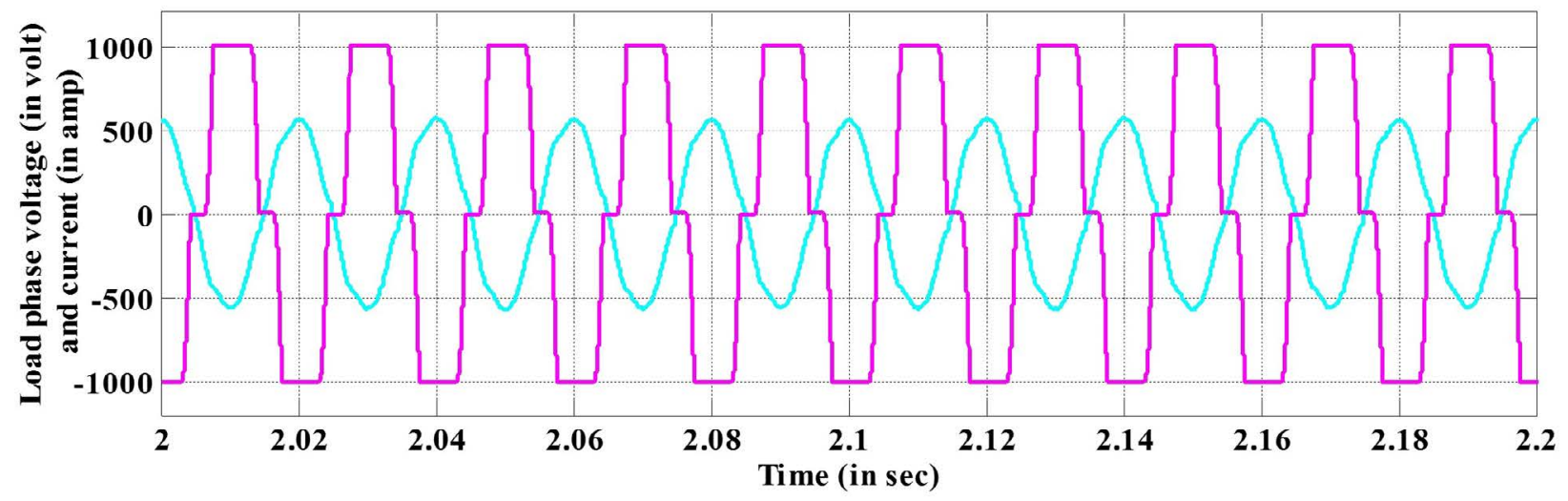

c)

Figure 12: a) Three phase load voltages (in Volt) and currents (in Amp); b) Enlarged view of the Figure 12a; c) Load phase voltage (in Volt) and current (in Amp). 

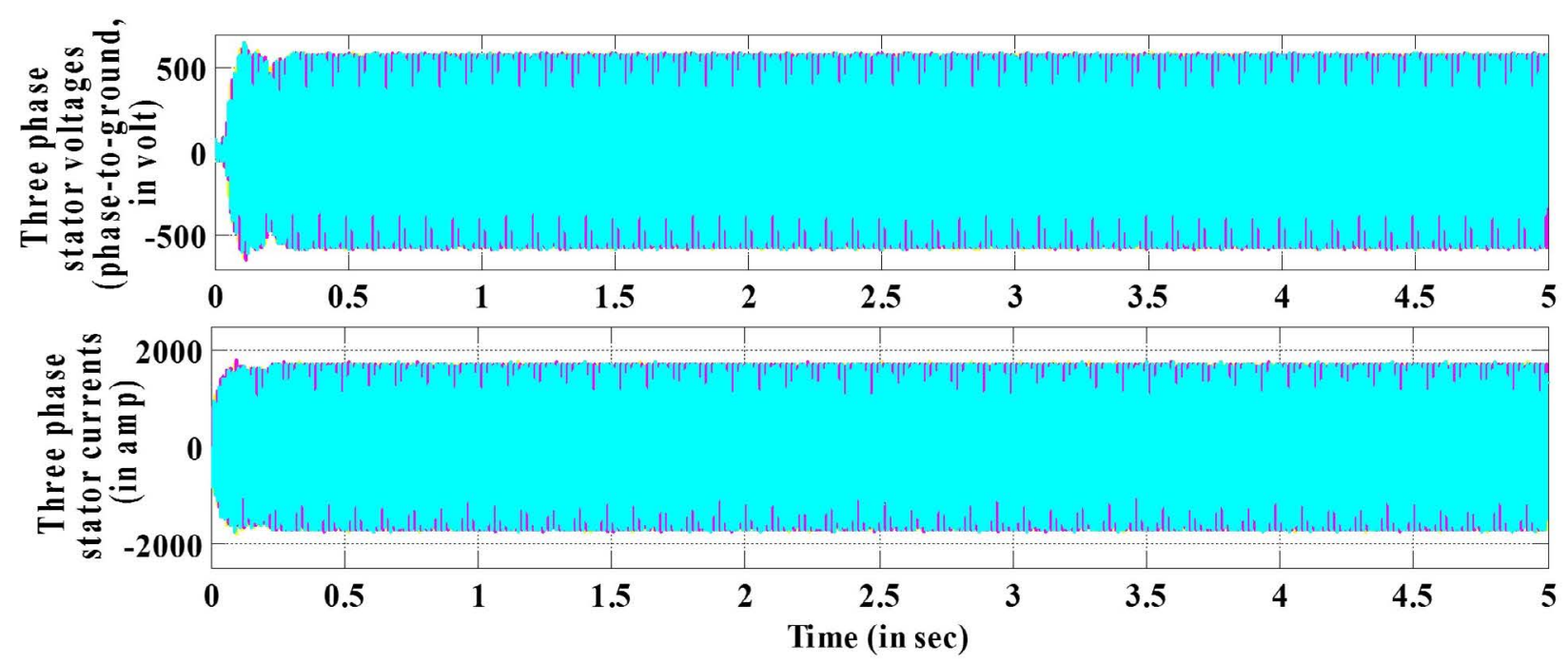

a)
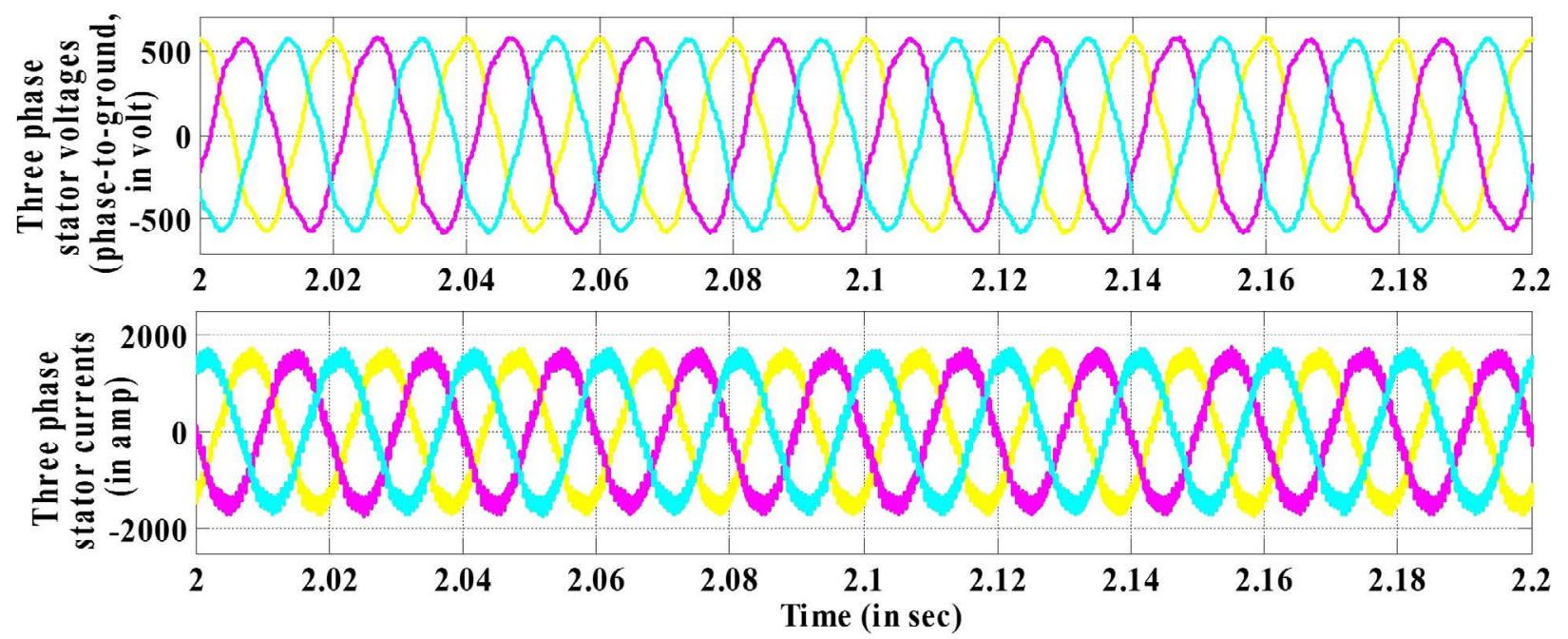

b)

Figure 13: a) Three phase stator voltages and currents; b) Enlarged time ( 2 to $2.2 \mathrm{sec}$ ) view of the Figure 13a.

$A$ is connected over the simulation time i.e. 0 to $5 \mathrm{sec}$. A constant wind speed $11 \mathrm{~m} / \mathrm{s}$ is given to the wind energy system. In order to obtained the performance analysis of the wind energy system with proposed control scheme under constant wind speed (at $11 \mathrm{~m} / \mathrm{s}$ ) and constant non-linear load (1000 A) condition, observations are done on its various parameters such as load voltage \& current, stator voltage \& current, frequency at the stator/ load terminal or at PCC, THD of stator and/or load voltage, THD of stator current, THD of load current, stator/load side converter/APF current, DC link voltage, DFIG speed and electromagnetic torque. Variations in these parameters are recorded as the results of simulation study and they are shown in Figure 12, Figure 13, Figure 14, Figure 15, Figure 16, Figure 17 and Figure 18.

In Figure 12a three phase load voltages and load currents are shown. The load voltages are constant at $398.38 \mathrm{Vrms}$ (or $563.39 \mathrm{~V}$ peak) due to constant stator voltages, the load currents are also constant due to constant load. Figure $12 \mathrm{~b}$ shows the enlarged ( $2 \mathrm{sec}$ to $2.2 \mathrm{sec}$ ) view of Figure 12a and load phase voltage and current (from $2 \mathrm{sec}$ to $2.2 \mathrm{sec}$ ) is shown in Figure 12c. Three phase stator voltages and currents are shown in Figure 13a and stator voltages are constant at their reference value i.e. $398.38 \mathrm{Vrms}$ (or $563.39 \mathrm{~V}$ peak) and 


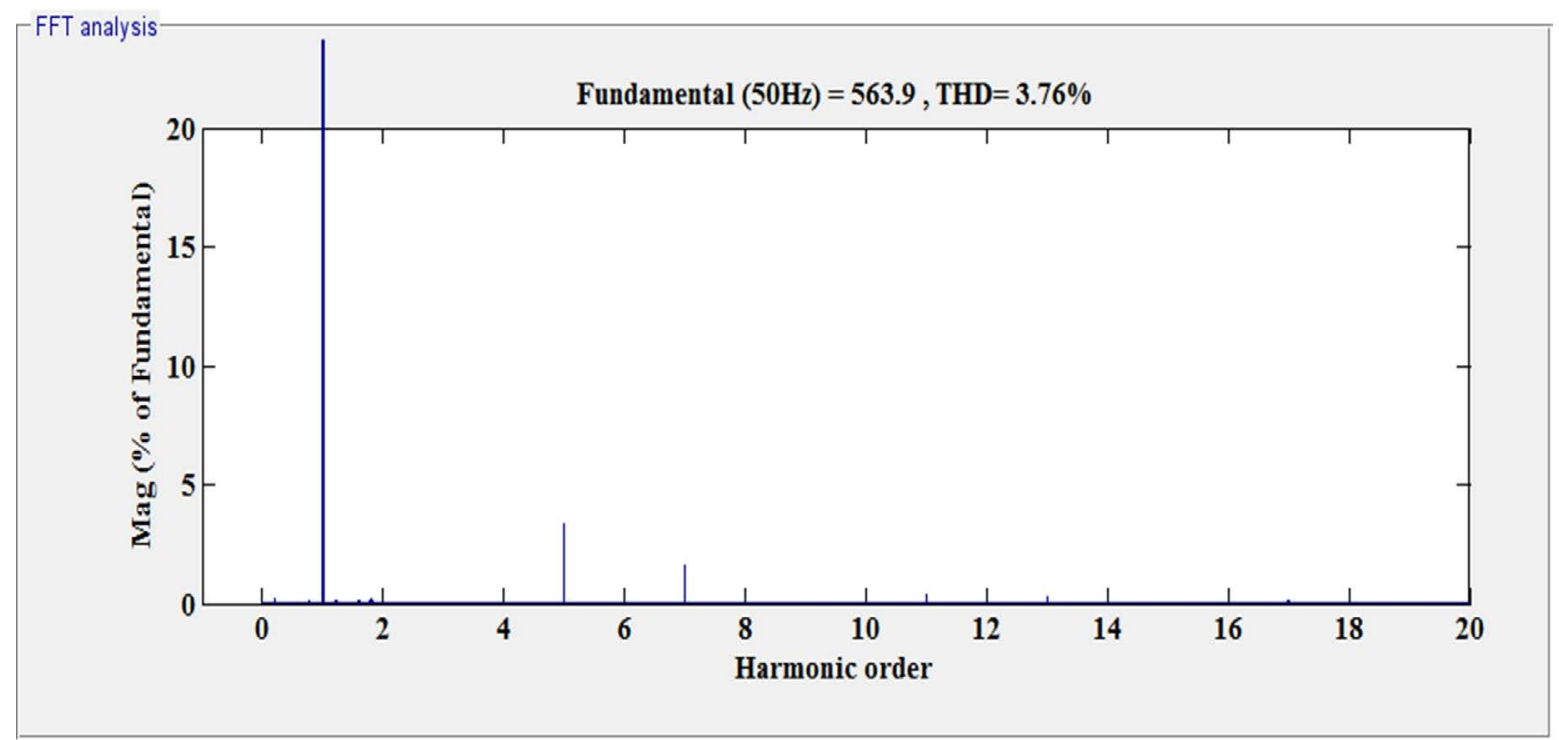

a)

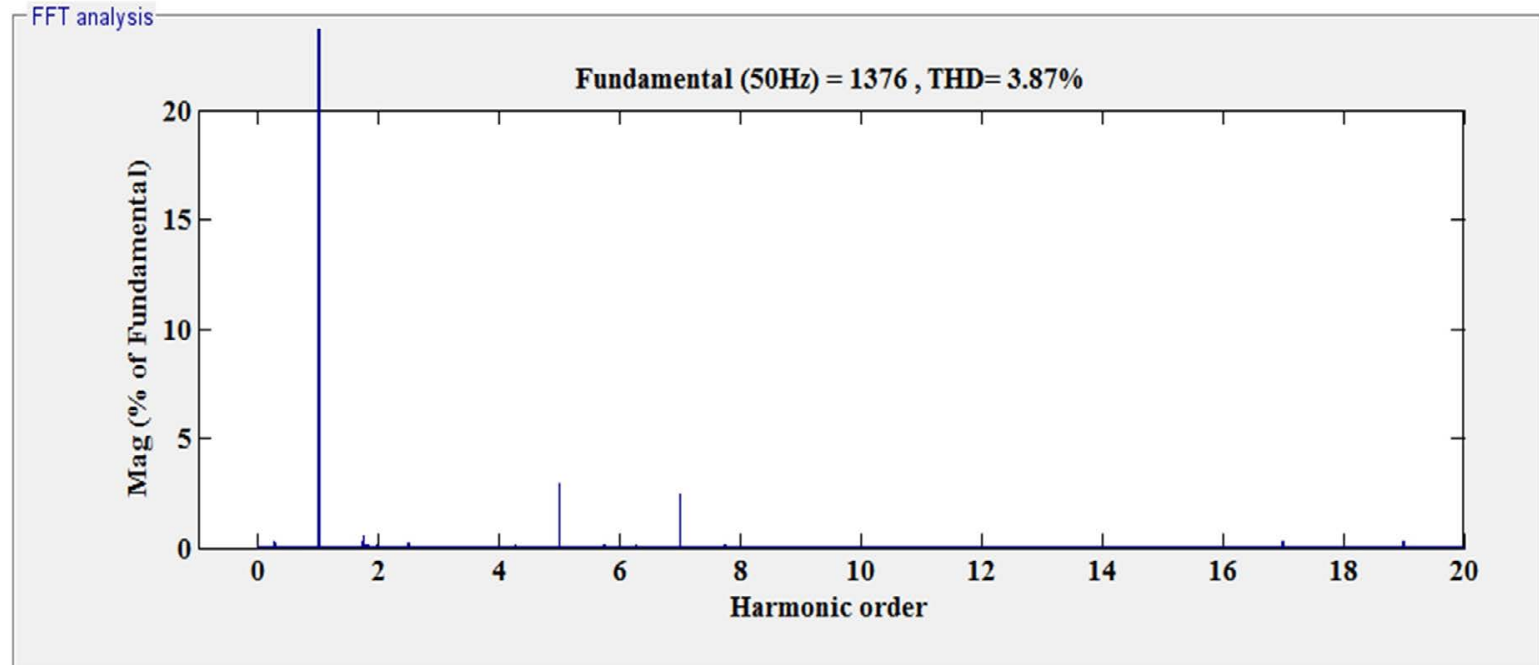

b)

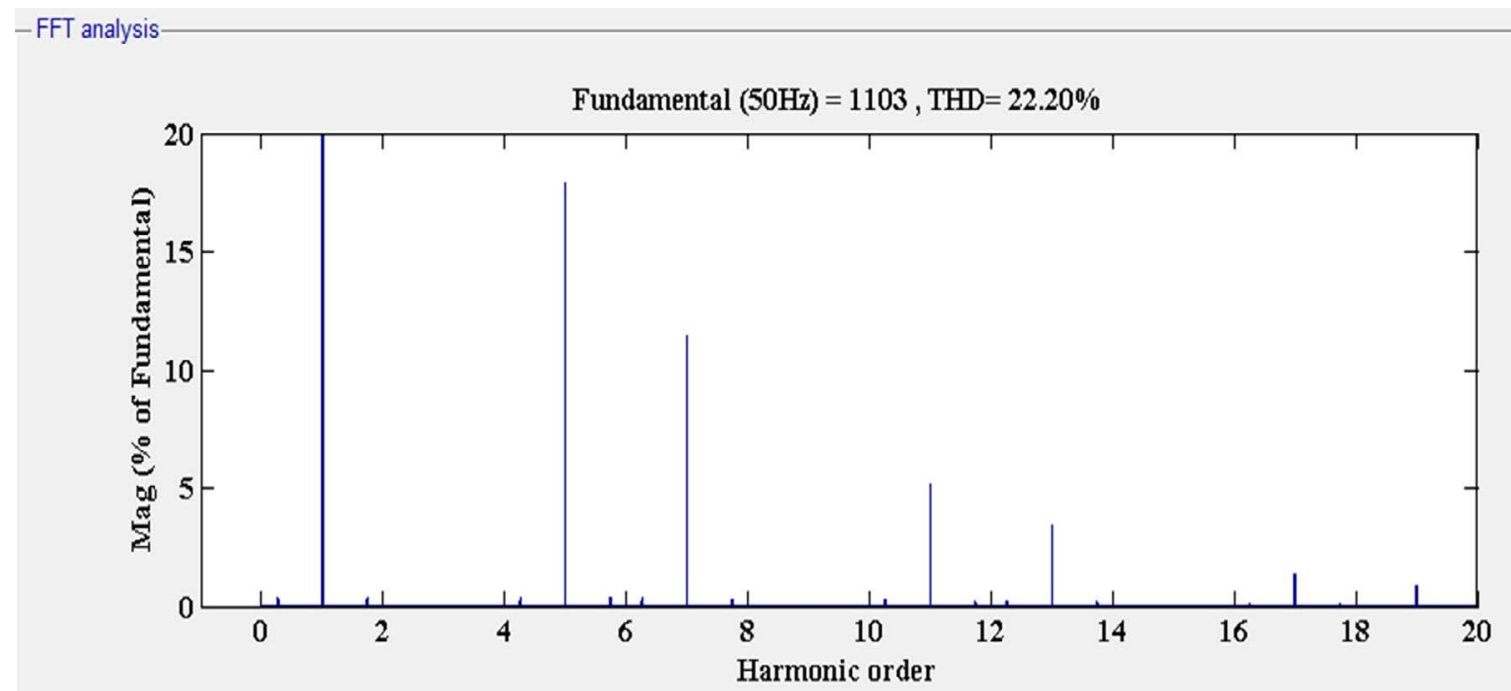

c)

Figure 14: THD analysis of the: a) Stator (and/or load) voltage; b) Stator current; c) Load current. 


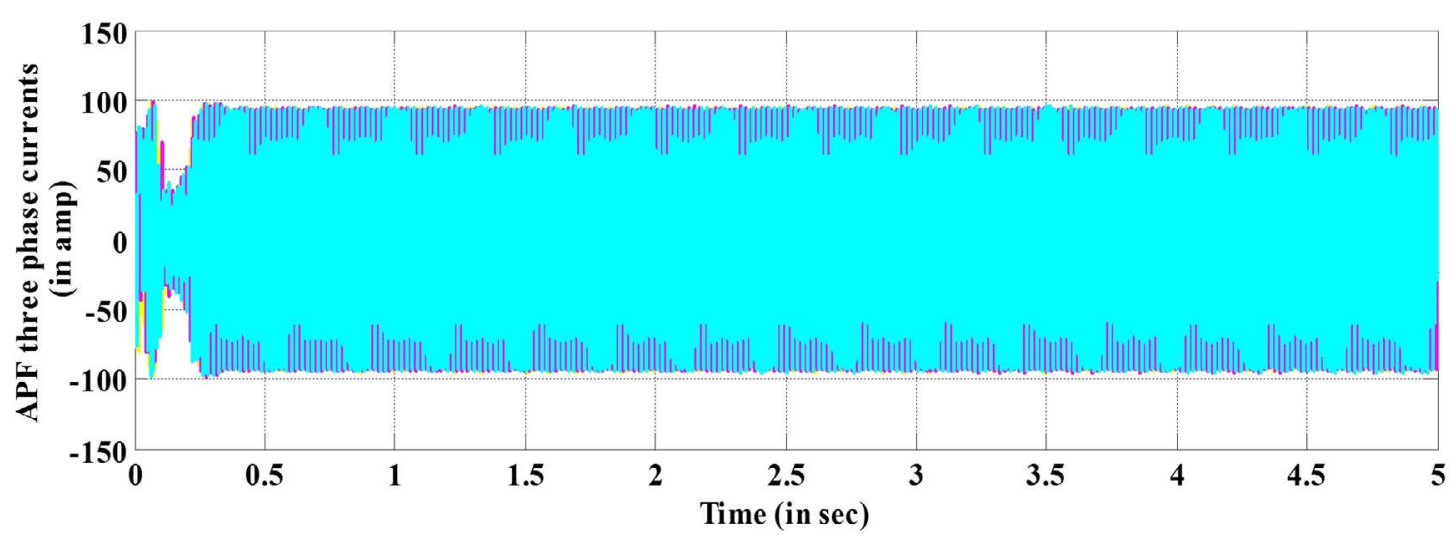

a)

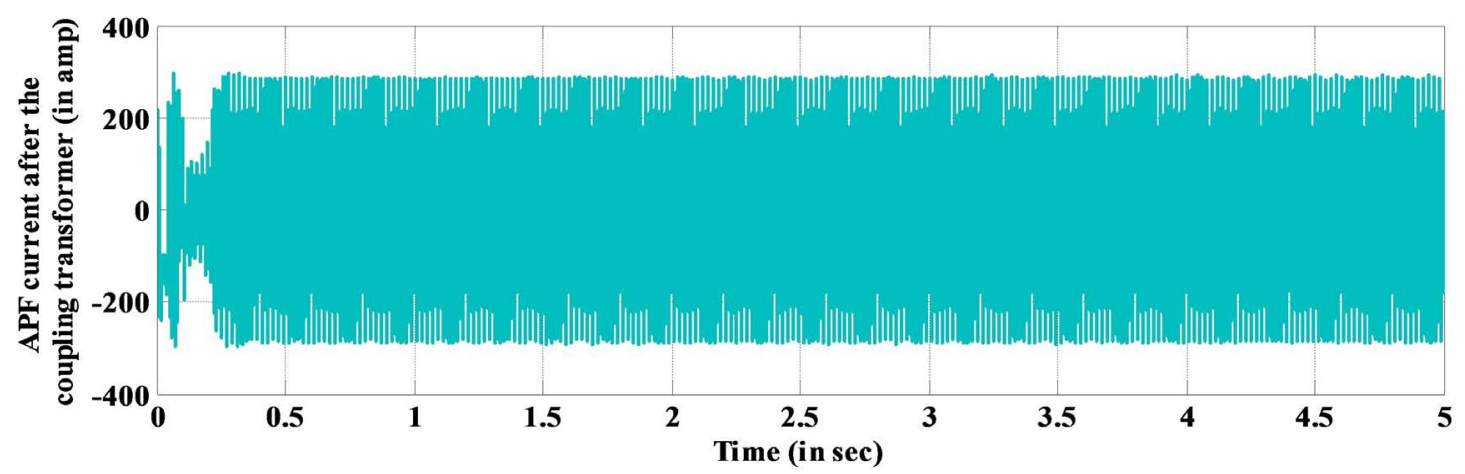

b)

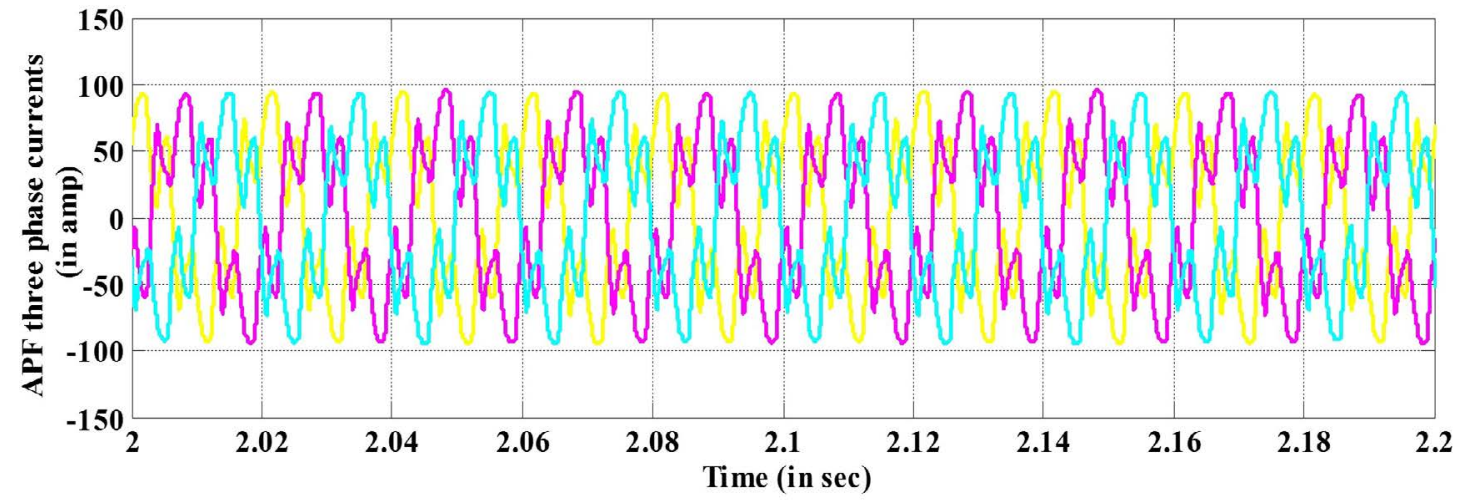

c)

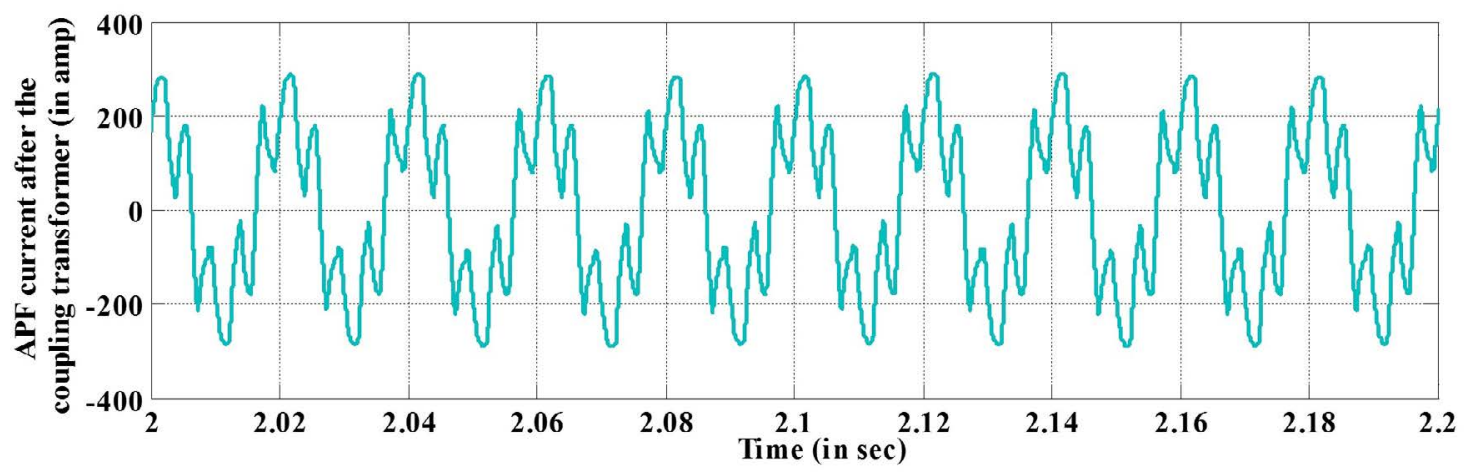

d)

Figure 15: a) Three phase APF currents; b) APF current after the coupling transformer; c) Enlarged view of Figure 15a; d) Enlarged view of Figure 15b. 
stator currents are also constant due to constant load. The enlarged ( $2 \mathrm{sec}$ to $2.2 \mathrm{sec}$ ) view of Figure 13a is shown in Figure 13b. THD analysis of the stator/load voltage, stator current and load current
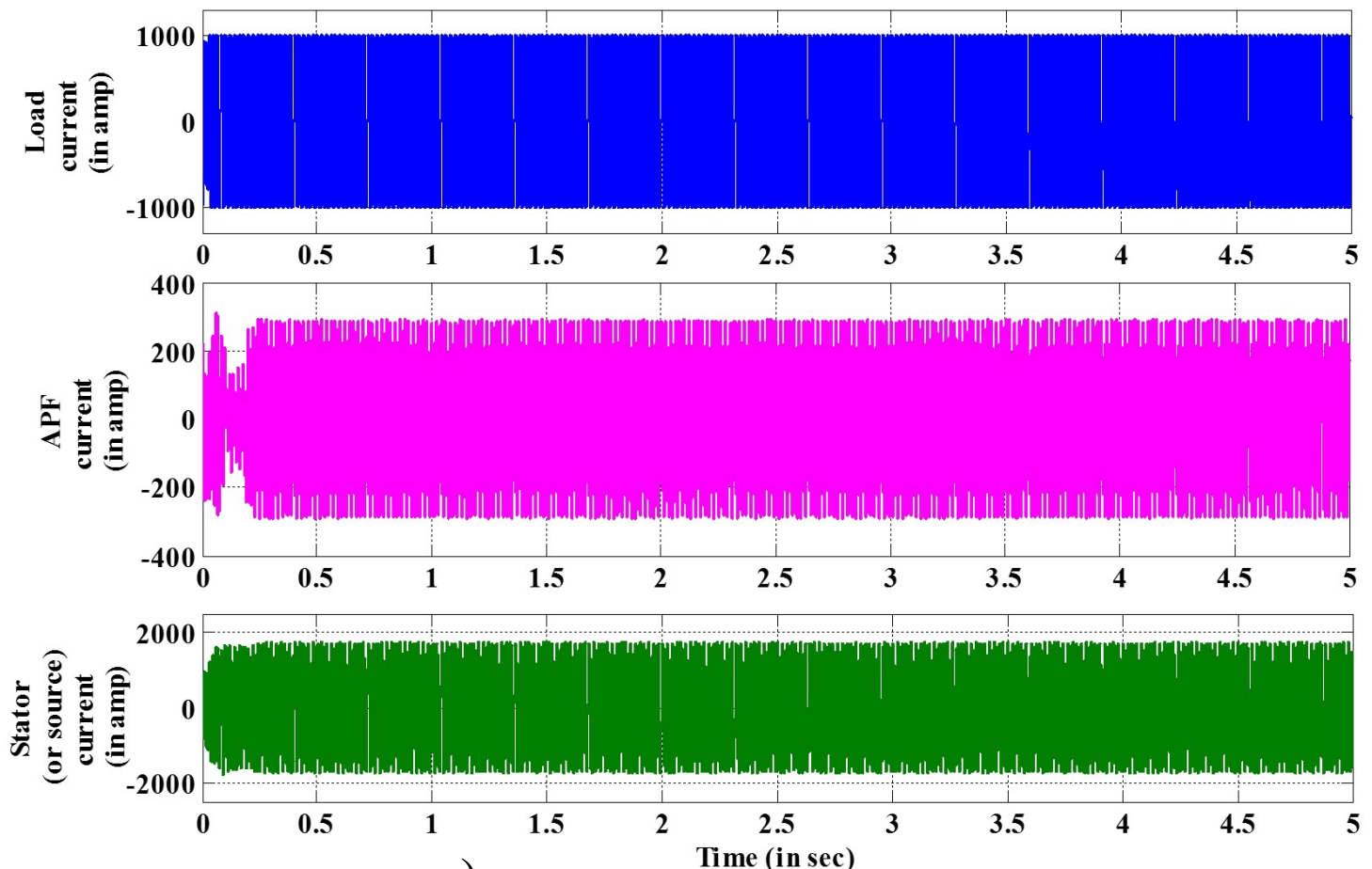

a)
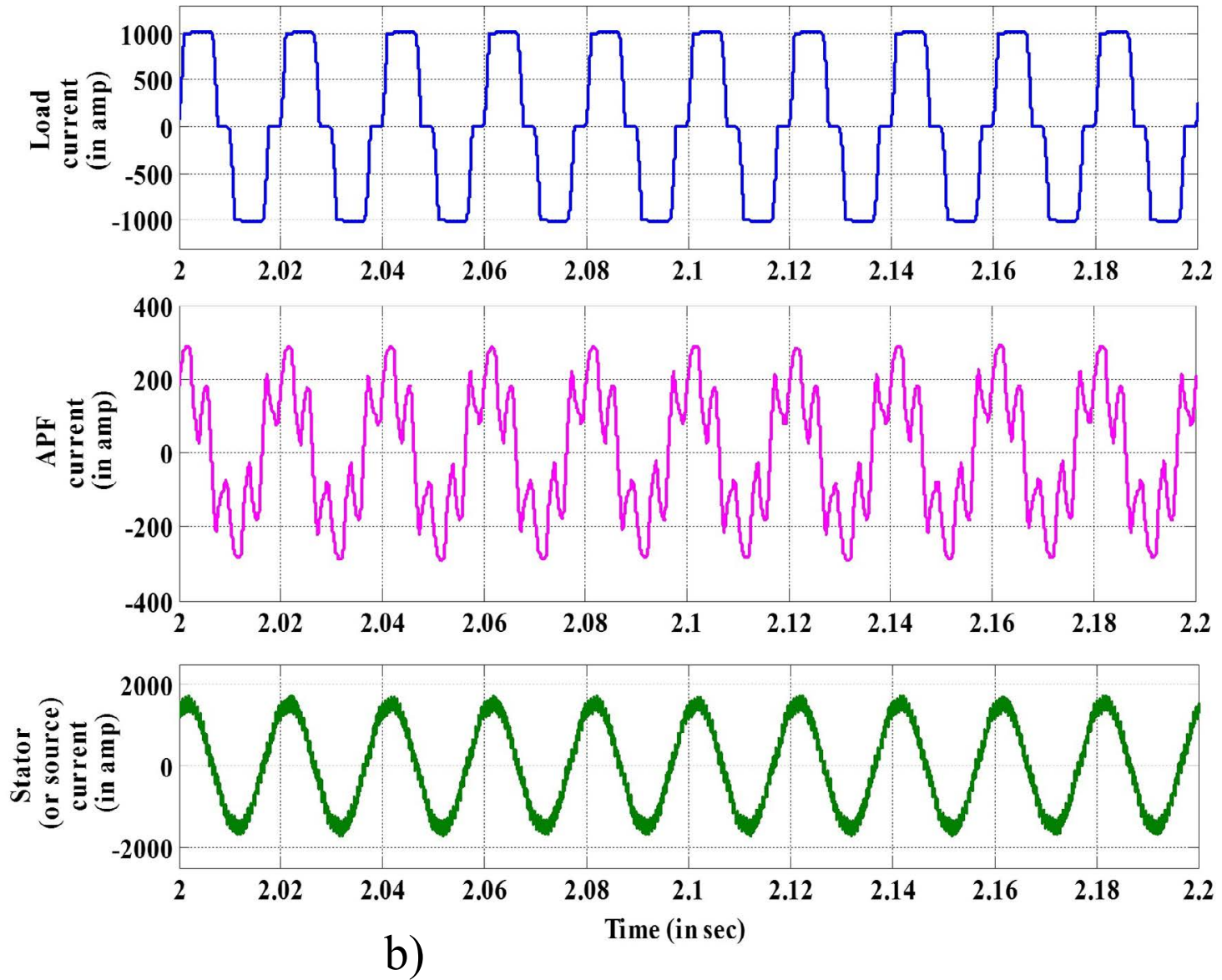

Figure 16: a) Combined representation of Load, APF and stator currents; b) Enlarged view of Figure 16a. 


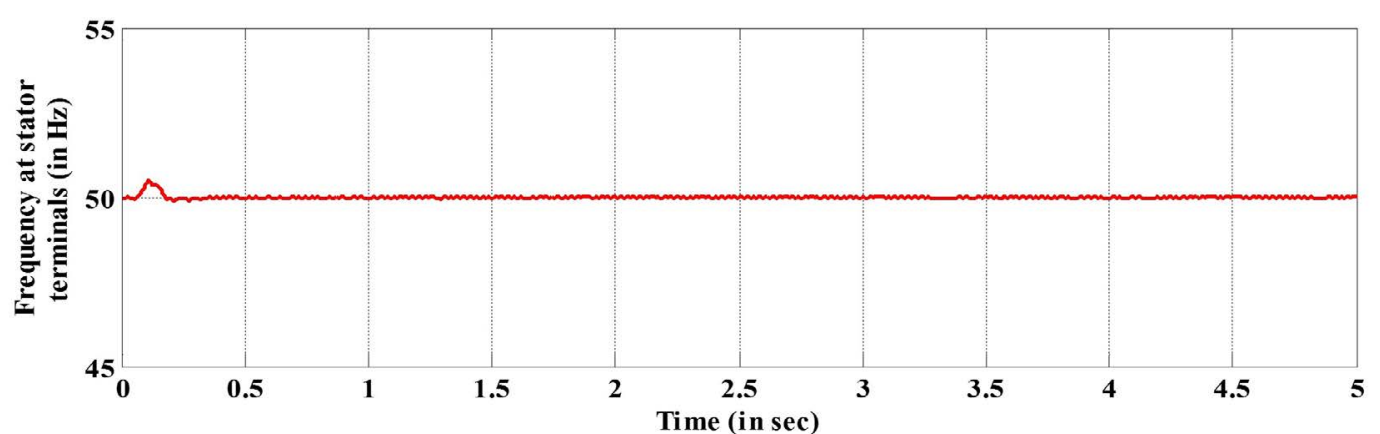

a)

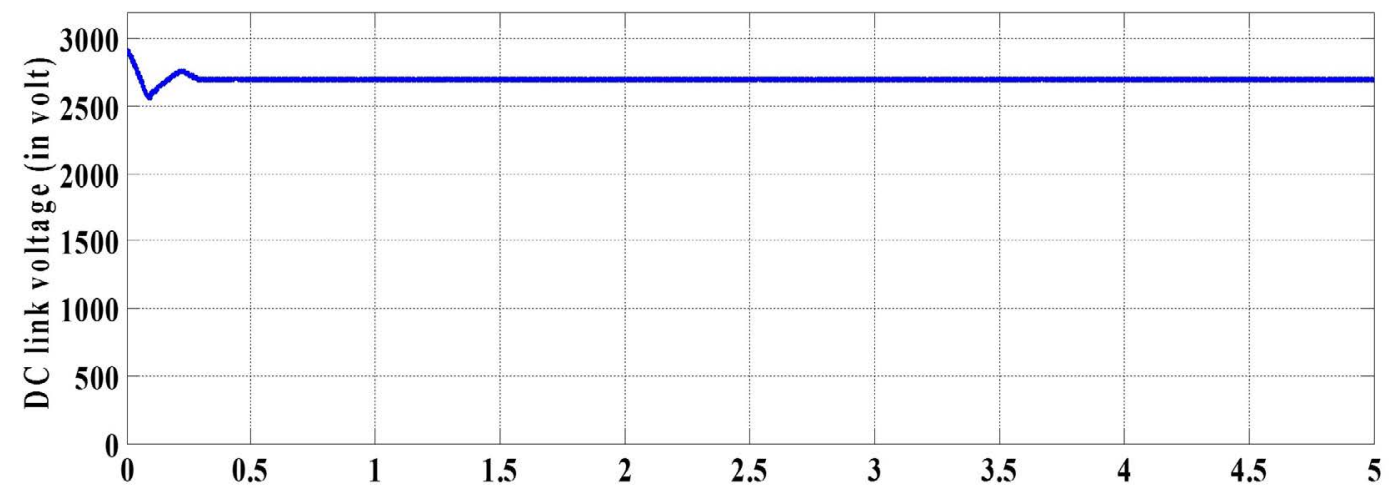

b) Time (in sec)

Figure 17: a) Frequency at the stator terminals or PCC (in Hz); b) DC link voltage (in Volt).

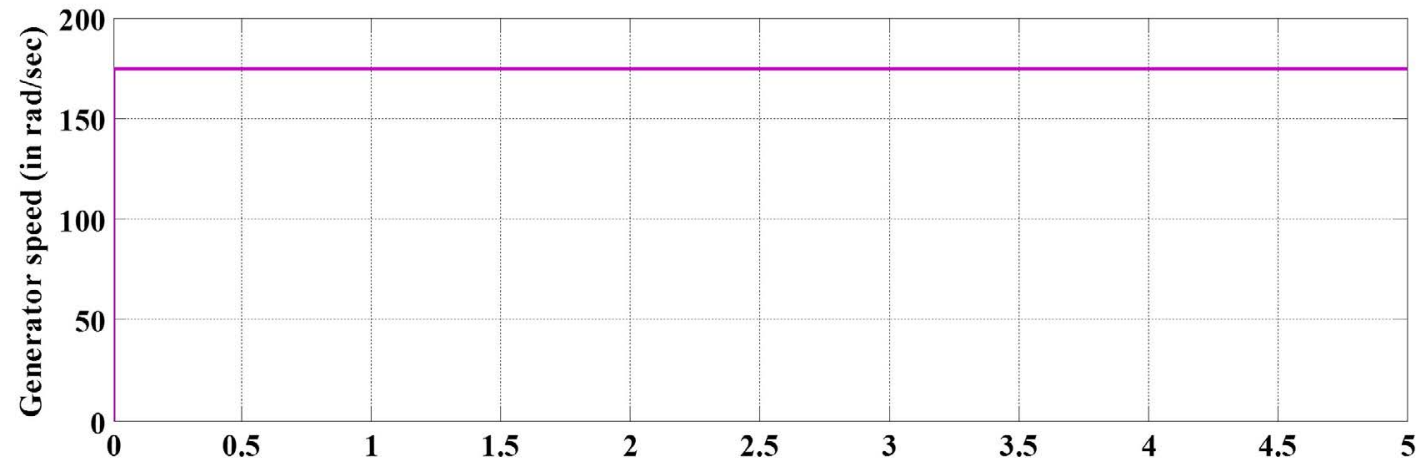

a)

Time (in sec)

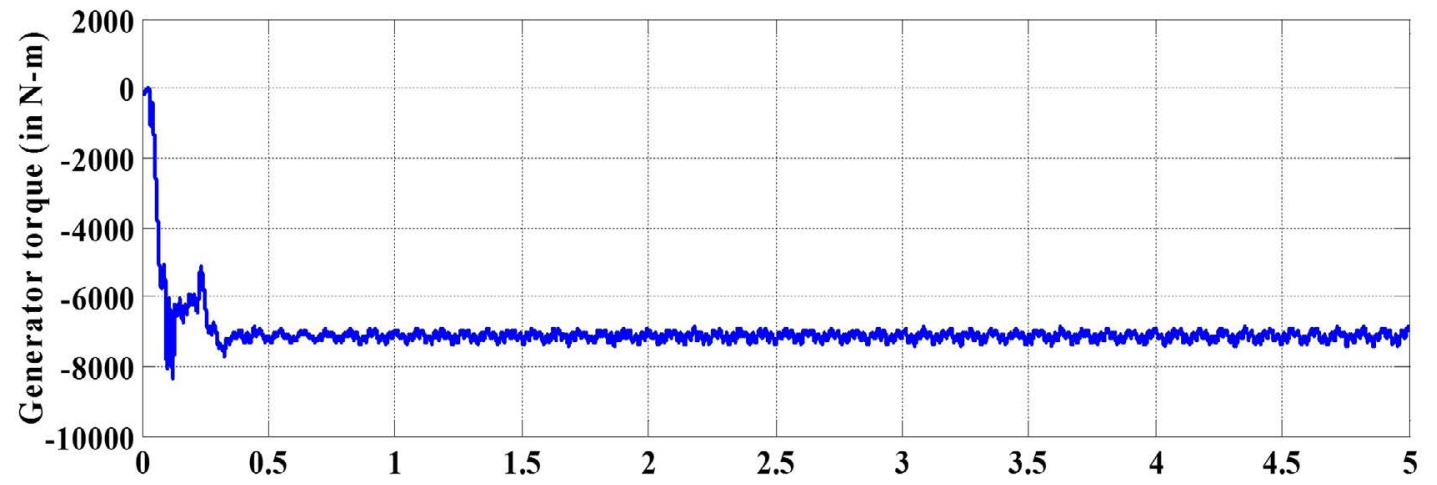

b)

Time (in sec)

Figure 18: a) Generator speed (in rad/sec); b) Generator torque (in N-m). 
are shown in Figure 14. The percentage (\%) THD of stator/load (because both are same) voltage, stator current and load current are 3.76\%, 3.87\%, and $22.20 \%$ respectively. Higher THD value of the load current is compensated by the stator/load side converter, which acts as a shunt active power filter. Three phase shunt active power filter (APF), i.e. stator/load side converter, currents are shown in Figure 15a and enlarged ( $2 \mathrm{sec}$ to $2.2 \mathrm{sec}$ ) view of Figure 15a is shown in Figure 15c. The APF current after the coupling transformer is given in Figure 15b and enlarged ( $2 \mathrm{sec}$ to $2.2 \mathrm{sec}$ ) view of this is shown in Figure $15 \mathrm{~d}$. The combined representation of load, APF and stator currents is shown in Figure 16a and enlarged (2 sec to $2.2 \mathrm{sec}$ ) view of Figure 16a is shown in Figure 16b. Figure 17a and Figure 17b represents the frequency at the stator terminals or PCC and DC link voltage respectively. Both of these quantities are constant at reference values i.e. $50 \mathrm{~Hz}$ and $2700 \mathrm{~V}$ respectively. Figure 18a and
Figure $18 \mathrm{~b}$ represents the generator speed and torque respectively. Due to constant wind speed the generator speed is constant. With the constant load, torque is also constant.

\section{Consider the effect on constant load under variable wind speed}

The performance of wind energy system can be observed under variaable wind speed for constant load. Simulation studies are performed for real wind condition. Sudden variation/increase (or gust) in wind speed from $11 \mathrm{~m} / \mathrm{s}$ to $14 \mathrm{~m} / \mathrm{s}$ at 3 sec. A non-linear load of $1000 \mathrm{~A}$ is connected for complete simulation period i.e. 0 to $5 \mathrm{sec}$. Various simulation parameters of WES are observed for the analysis of the performance of WES with proposed control scheme such as: Load voltage \& current, stator voltage \& current, frequency at the stator/ load terminal or at PCC, stator/load side converter/ APF current, DC link voltage, DFIG speed and
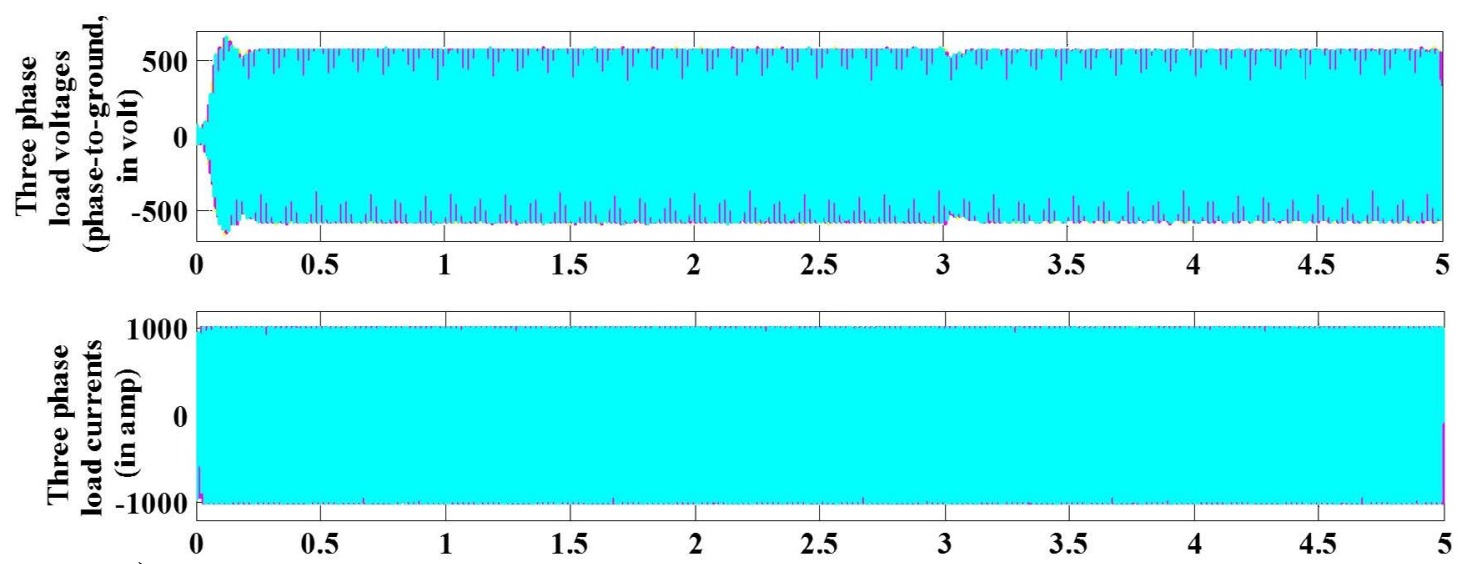

a)

Time (in sec)
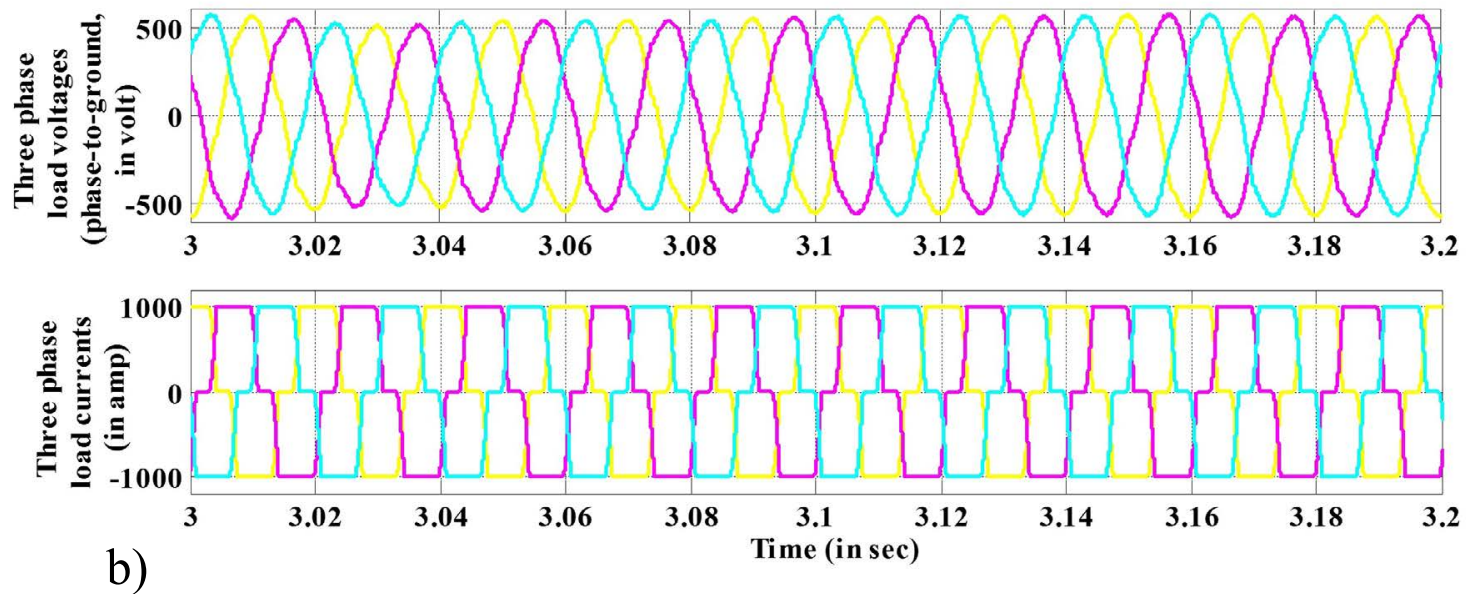

Figure 19: a) Three phase load voltages (in Volt) and currents (in Amp); b) Enlarged view of the Figure 19a in between $3 \mathrm{sec}$ to $3.2 \mathrm{sec}$. 
electromagnetic torque etc. They are shown here in Figure 19, Figure 20, Figure 21, Figure 23 and Figure 24.

In Figure 19a three phase load voltages and load currents are shown under the variable wind speed (there is sudden increase in wind speed from $12 \mathrm{~m} / \mathrm{s}$ to $15 \mathrm{~m} / \mathrm{s}$ at $3 \mathrm{sec})$. The load voltages are constant at $398.38 \mathrm{Vrms}$ (or $563.39 \mathrm{~V}$ peak) due to constant stator voltages and the load currents are also constant due to constant load. Figure 19b shows the enlarged ( $2.9 \mathrm{sec}$ to $3.2 \mathrm{sec}$ ) view of Figure 19a around the $3 \mathrm{sec}$. Three phase stator voltages and currents are shown in Figure 20a in this case. Stator voltages are constant at their reference value i.e.
398.38 Vrms (or 563.39 V peak) and stator currents are also constant due to constant load. The enlarged (2.9 sec to $3.2 \mathrm{sec}$ ) view of Figure 20a is shown in Figure 20b. Three phase shunt active power filter (APF) (i.e. stator/load side converter) currents and APF current after the coupling transformer are shown in Figure 21a. The enlarged (from $2.9 \mathrm{sec}$ to $3.2 \mathrm{sec}$ ) view of Figure 23a is shown in Figure 21b. There is some variation in the magnitudes of the APF or filter currents. It is due to the fact that as the generator deviates more from the synchronous speed (above or below), rotor current frequency, rotor cu loss and required magnetization current is increased. The combined representation of load, APF and stator currents are shown in Figure
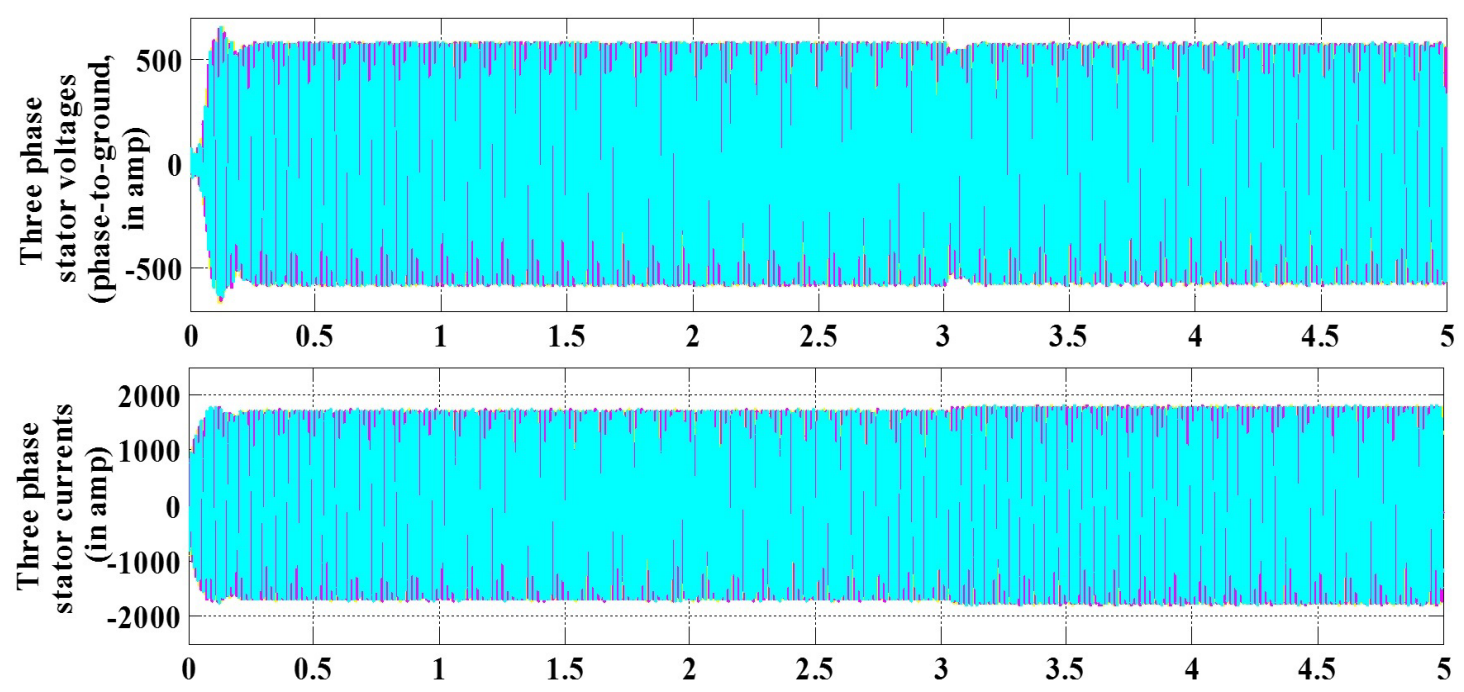

a)

Time (in sec)
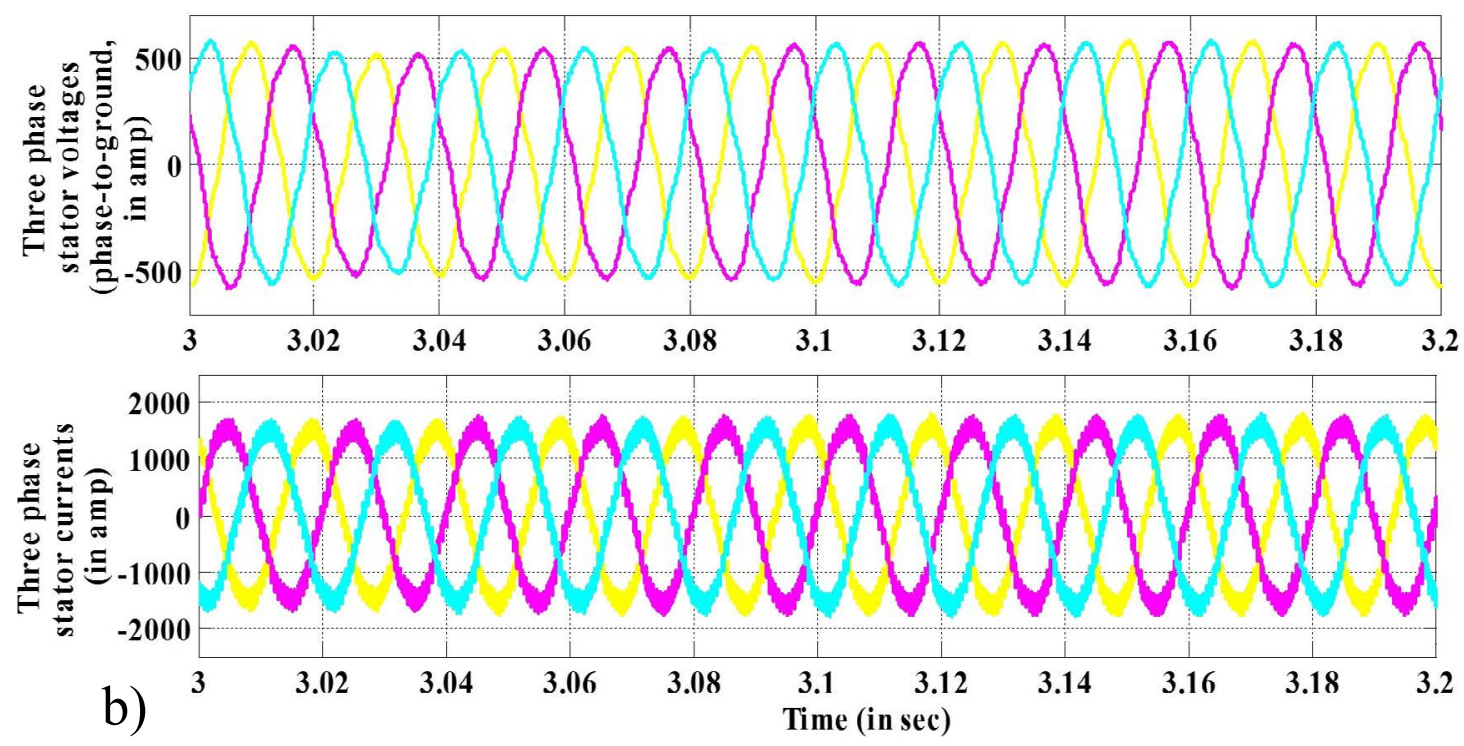

Figure 20: a) Three phase stator voltages (in Volt) and currents (in Amp); b) Enlarged view of the Figure 20a in between $3 \mathrm{sec}$ to $3.2 \mathrm{sec}$. 

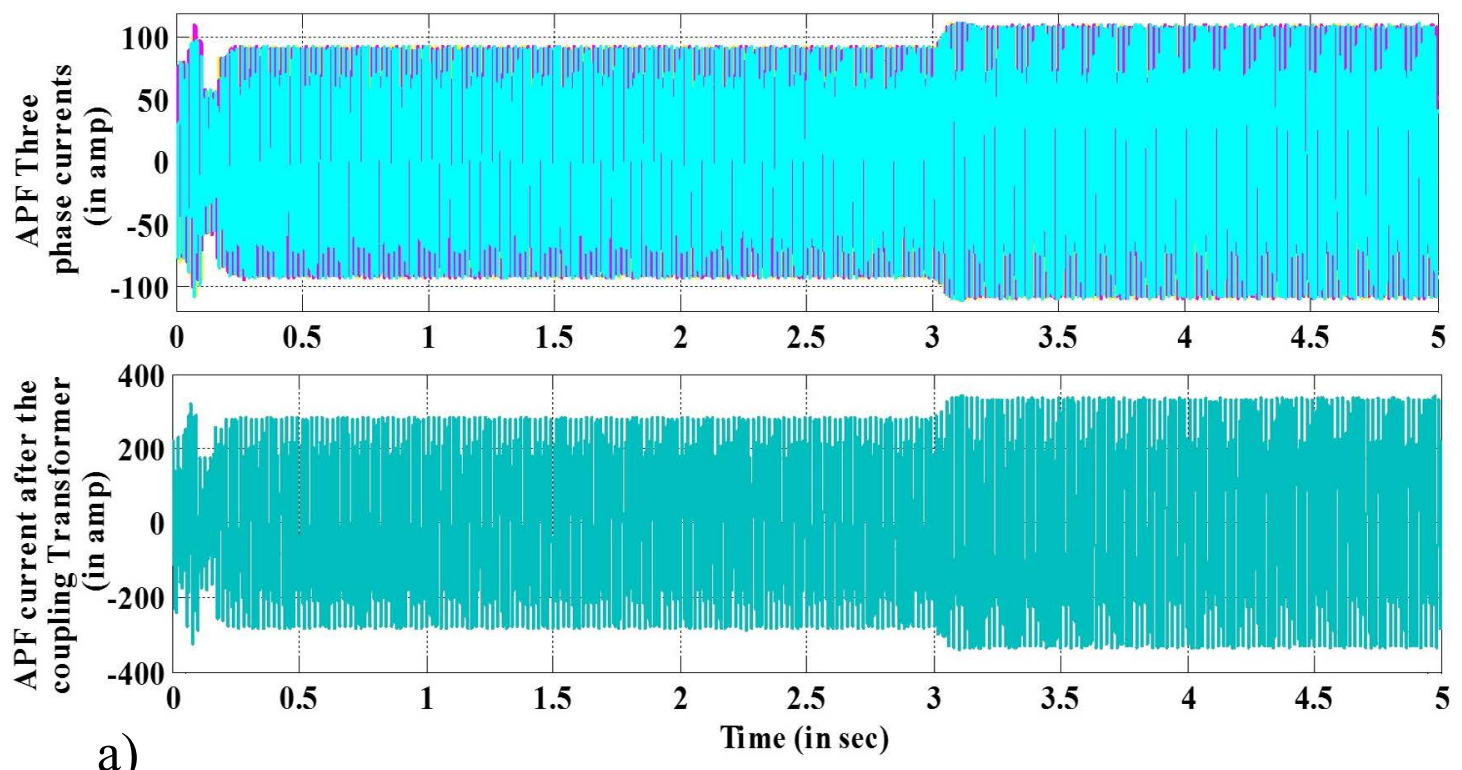

a)
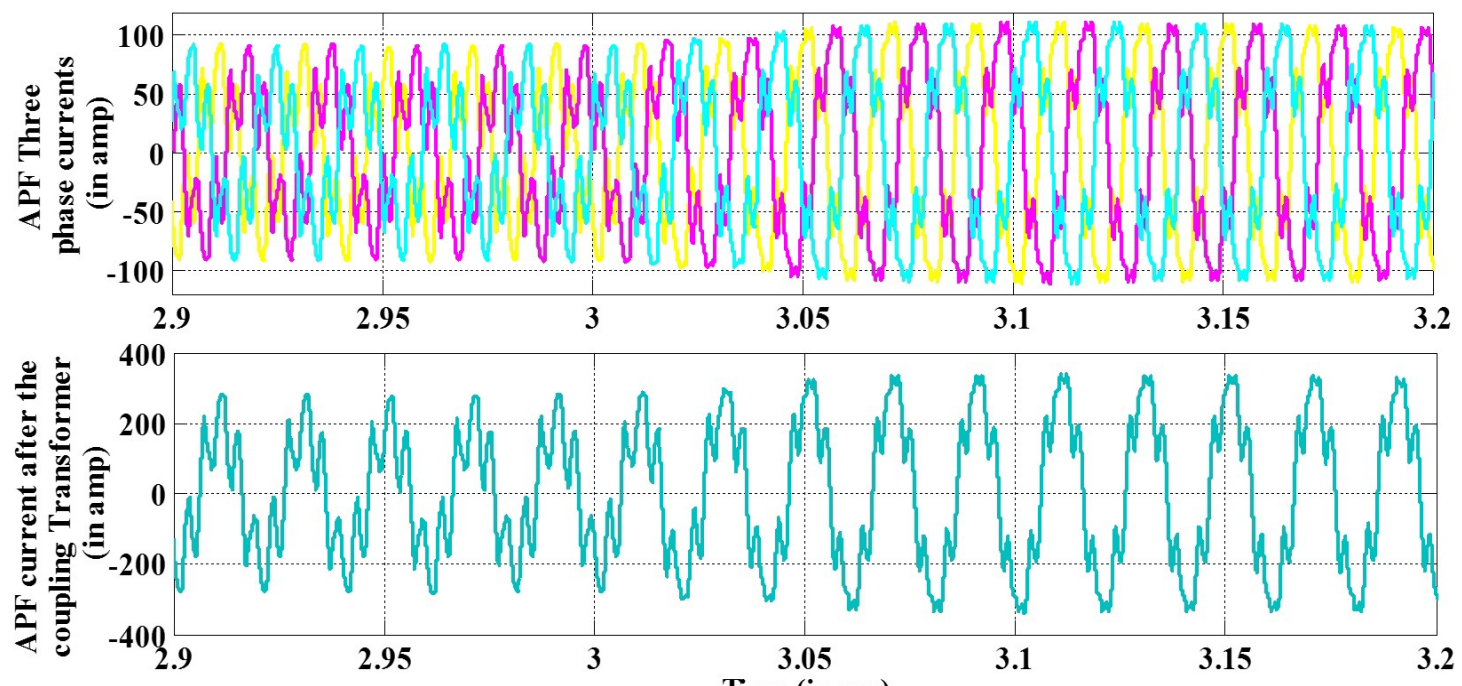

b)

Time (in sec)

Figure 21: a) APF Three phase currents (in Amp) and APF current (in Amp) after the coupling transformer; b) Enlarged view of Figure 21a in between $3 \mathrm{sec}$ to $3.2 \mathrm{sec}$.

22a. Figure $22 \mathrm{~b}$ represents the enlarged view of Figure 22a from $2.9 \mathrm{sec}$ to $3.2 \mathrm{sec}$. Figure 23a and Figure $23 \mathrm{~b}$ represents the frequency at the stator terminals or PCC and DC link voltage respectively. Both of these quantities are constant at reference values i.e. $50 \mathrm{~Hz}$ and $2700 \mathrm{~V}$ respectively with some variation at the wind speed variation instant. Figure 24a and Figure 24b represents the generator speed and torque respectively. Generator speed is variable due to the wind speed. So as the result, torque is also variable.

\section{Conclusion}

In this paper a complete study of autonomous wind energy generation system has been presented. A control technique based on stator flux-oriented reference frame has been used to regulate the stator voltage and frequency via the rotor side converter. The shunt active power filter function has been effectively embedded with the conventional control of load/stator side converter. Rotor side converter using speed sensor/encoder for speed sensing based on stator flux oriented controlled and load/stator side converter using shunt active power filtering technique for compensation of load harmonics. Different possible cases have been taken to prove the performance of present control scheme. Different performance parameter has been record- 

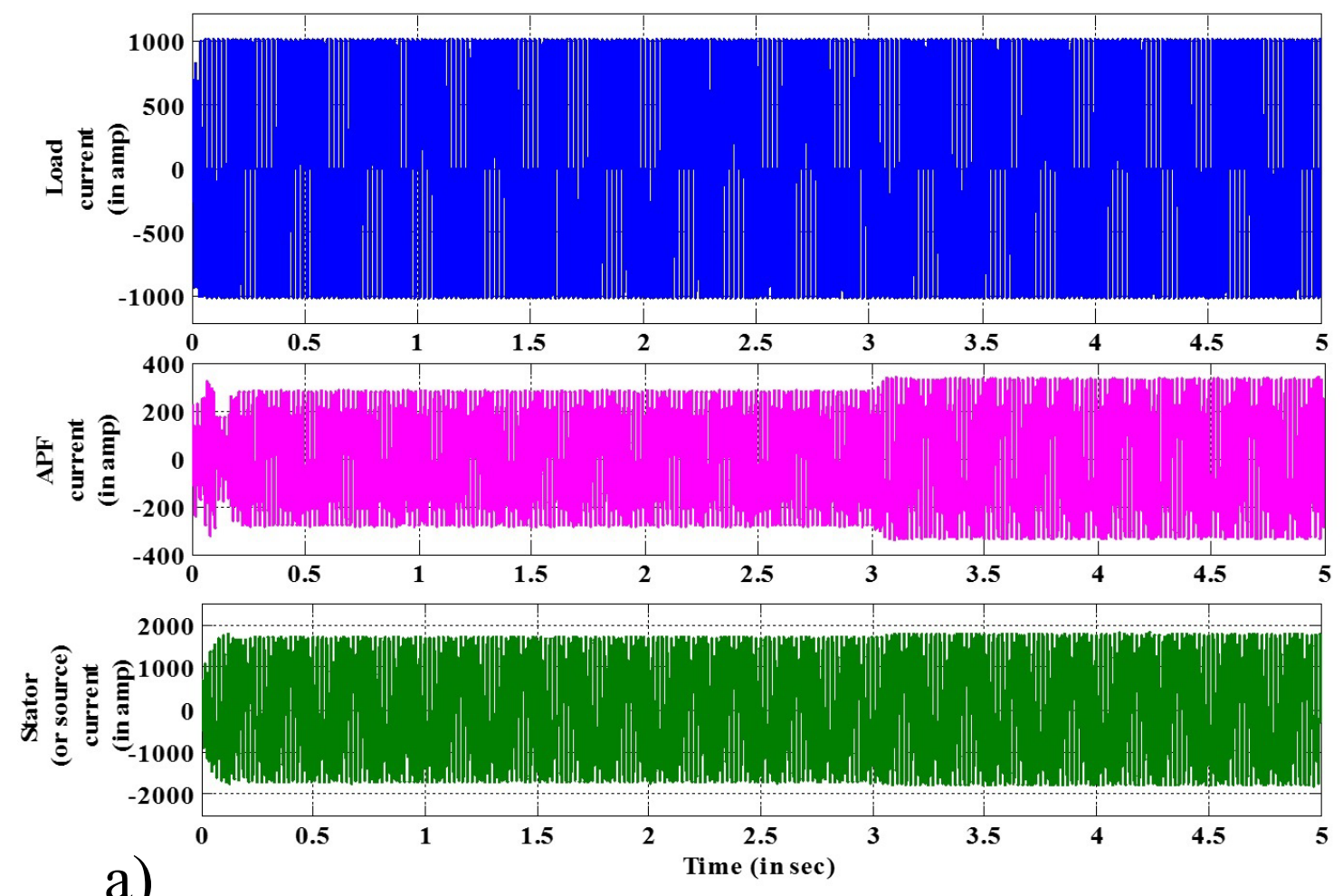

a)
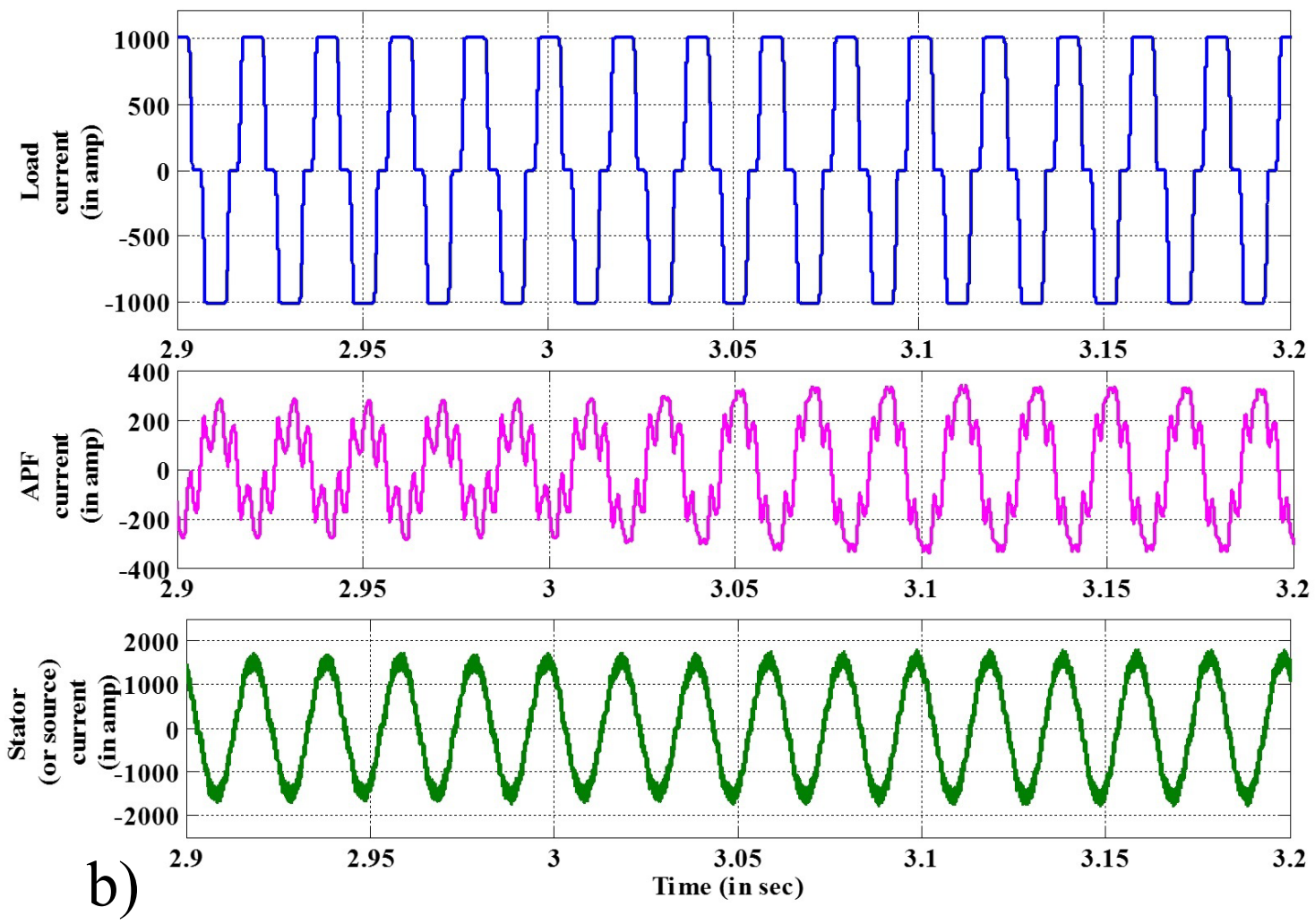

Figure 22: a) Combined representation of Load, APF and stator currents (in amp); b) Enlarged view of Figure 22a in between $3 \mathrm{sec}$ to $3.2 \mathrm{sec}$.

ed to show the effectiveness of presented system such as active and reactive power control, stator side voltage and frequency, stator/load currents, filter currents DC link voltage etc. Using simulation studies through MATLAB/SIMULINK, the outcome is satisfactory for transient and steady state for au- 


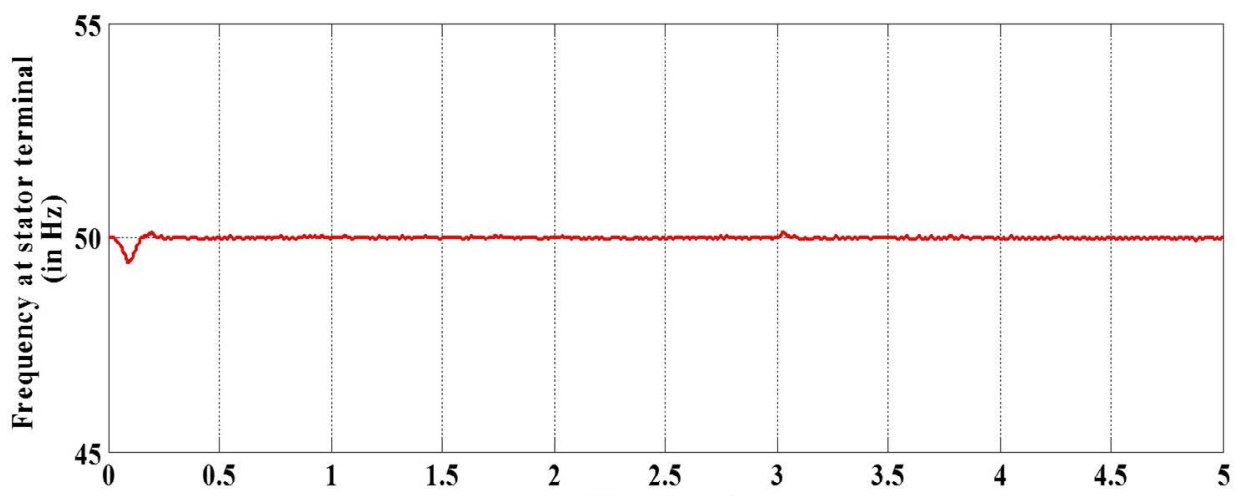

a)
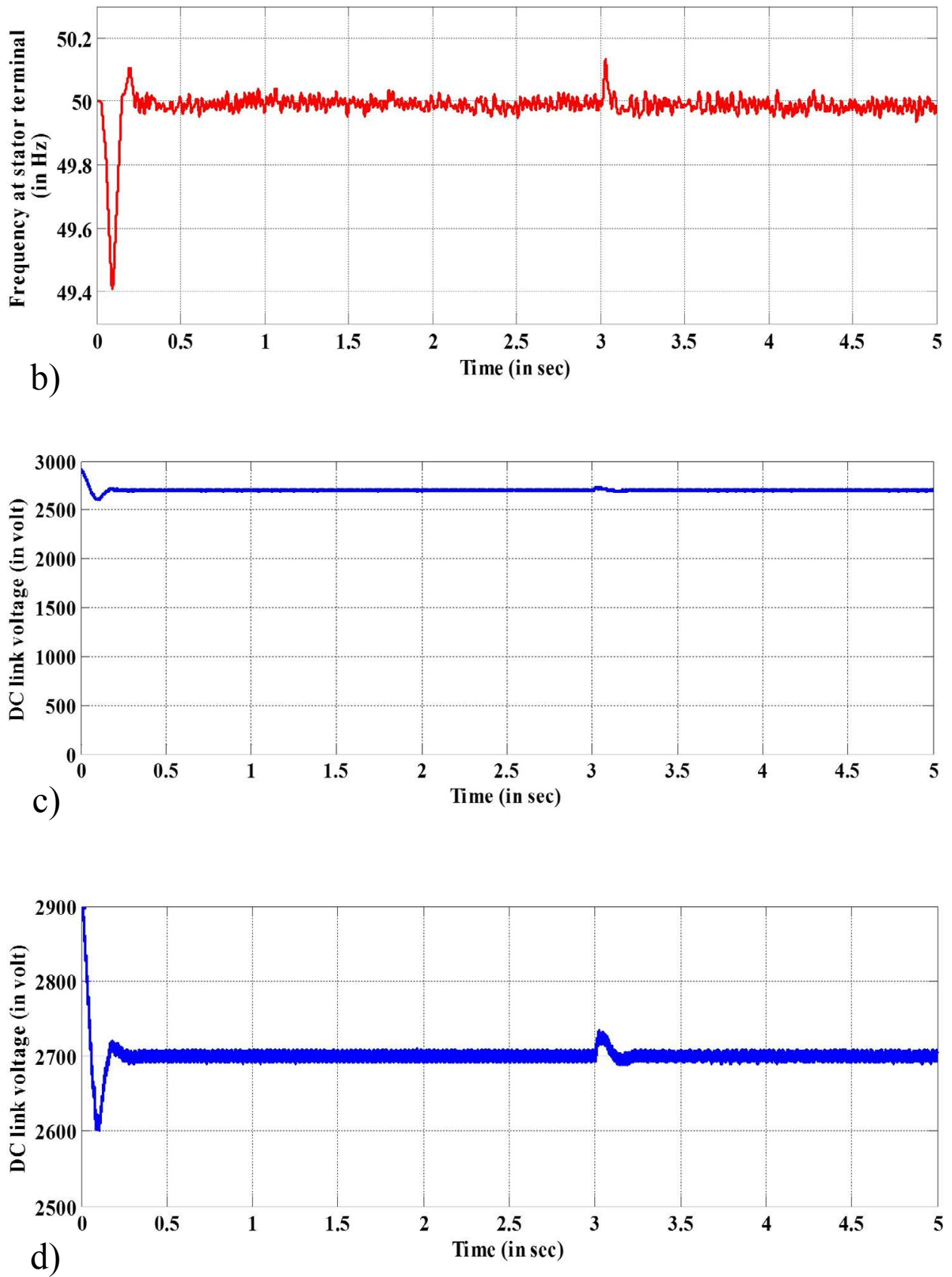

Figure 23: a) Frequency at the stator terminals or at PCC (in Hz); b) Enlarged view of Figure 23a; c) DC link voltage (in Volt); d) Enlarged view of Figure 23c. 

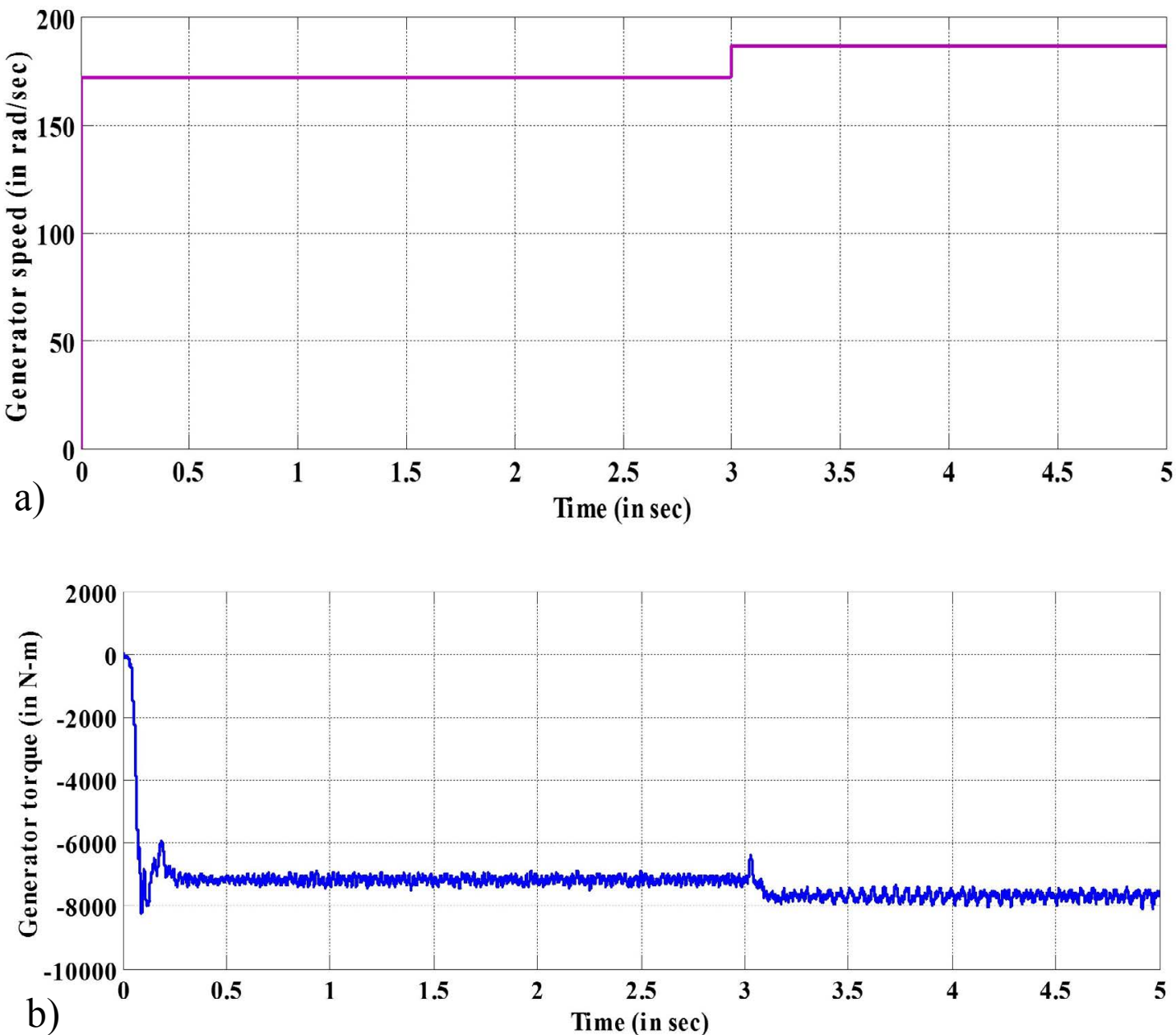

Figure 24: a) Generator speed (in rad/sec); b) Generator torque (in N-m).

tonomous mode of operation. The results of DFIG system, in terms of active power; reactive power and DC link voltages, generator torque and speed under the isolated ( $R-L$ type) load and non-linear load. This work will be extended in future for hardware testing.

\section{References}

1. Z Chen, JM Guerrero, F Bleiberg (2009) A review of the state of the art of power electronics for wind turbines. IEEE Trans on Power Electron 24: 18591875.

2. RD Shukla, RK Tripathi, S Gupta (2010) Power electronics applications in wind energy conversion system: A review. IEEE International Conference on Power, Control and Embedded Systems.

3. RD Shukla, Amrita Singh, SP Singh (2012) Generators for variable speed wind energy conversion systems: A comparative study. International Journal of Energy Systems Computers and Control 3: 103-117.
4. O Carlson, J Hylander, K Thorborg (1996) Survey of variable speed operation of wind turbines. European Union Wind Energy Conference, Sweden, 406-409.

5. S Muller, M Deicke, RW De Doncker (2002) Doubly fed induction generator systems for wind turbines. IEEE Ind Appl Mag 8: 26-33.

6. RD Shukla, RK Tripathi (2013) Dynamic performance of DFIG based WECS under different voltage Sag. International Journal of Chemtech Research 5: 980992.

7. J Lopez, P Sanchis, X Roboam, L Marroyo (2007) Dynamic behavior of the doubly fed induction generator during three-phase voltage dips. Energy Convers IEEE Trans 22: 709-717.

8. RD Shukla, RK Tripathi (2012) Low voltage ride through ability of DFIG based wind energy conversion systems-I. Conference on Engineering \& Systems.

9. RD Shukla, RK Tripathi (2012) Low voltage ride through ability of DFIG based wind energy conversion systems-II. Conference on Engineering \& Systems. 
10.Y Zhou, P Bauer, J Ferreira, J Pierik (2009) Operation of grid-connected DFIG under unbalanced grid voltage condition. IEEE Transactions on Energy Conversion 24: 240-246.

11.S Li, TA Haskew, KA Williams, RP Swatloski (2012) Control of DFIG wind turbine with direct-current vector control configuration. IEEE Trans Sustainable Energy 3: 1-11.

12.M Kenan Döşoğlu (2016) A new approach for low voltage ride through capability in DFIG based wind farm. International Journal of Electrical Power \& Energy Systems 83: 251-258.

13.G Iwanski, W Koczara (2004) Sensorless standalone variable speed system for distributed generation. 35th IEEE PESC, Germany, 1915-1921.

14.G Iwanski, W Koczara (2004) Island operation of the variable speed induction generator. 4th IEEE International Power Electronics and Motion Control Conference 2: 896-901.

15.G Iwanski, W Koczara (2008) DFIG-based power generation system with UPS function for variablespeed applications. IEEE Trans Ind Electron, 55.

16.G Iwanski, W Koczara (2004) Simple autonomous sensorless generation system with wound induction machine. IEEE International Symposium on Industrial Electronics 2: 929-934.

17.G Iwanski, W Koczara (2006) Positive and negative sequence based sensorless control for stand-alone slip-ring generator. 12th EPE-PEMC, Portoroz, Slovenia, 555-560.

18.RD Shukla, RK Tripathi (2014) Speed-sensorless voltage \& frequency control in autonomous DFIG based wind energy systems. 2014 IEEE Australasian University Power Engineering Conference, Curtin University, Australia.

19.RD Shukla, RK Tripathi (2013) A Stand-alone wind energy conversion system using wound rotor induction machine. IEEE International Conference on Power, Energy and Control.

20.RD Shukla, RK Tripathi (2012) Topologies for Stand- alone DFIG based wind energy conversion system. 2nd IEEE International Conference on Power, Control and Embedded Systems.

21.RD Shukla, RK Tripathi (2014) A novel voltage and frequency controller for standalone DFIG based wind energy conversion system. Renewable and Sustainable Energy Reviews 37: 69-89.

22.R Pena, JC Clare, GM Asher (1996) Double fed induction generator using back-to-back PWM converters and its application to variable-speed wind-energy generation. Electric Power Applications, IEE Proceedings 143: 231-241.

23.RD Shukla, RK Tripathi (2012) Maximum power extraction schemes \& power control in wind energy conversion system. International Journal of Scientific \& Engineering Research 3: 1-7.

24.G Iwanski (2009) DFIG based standalone power system operating at low load conditions. 13th European Conference on Power Electronics and Applications.

25.B Hopfensperger, DJ Atkinson, RA Lakin (2000) Stator- flux oriented control of a doubly-fed induction machine without position encoder. IEEE Power Application 147: 241-250.

26. HM El-helw, SB Tennakoon (2008) Vector control of a doubly fed induction generator for standalone wind energy application. Wind Power to the Grid EPE Wind Energy Chapter 1st Seminar.

27.V Soares, P Verdelho, GD Marques (2000) An instantaneous active and reactive current component method for active filters. Power Electronics, IEEE Transactions 15: 660-669.

28.RD Shukla, RK Tripathi (2015) Isolated wind power supply system using double-fed induction generator for remote areas. Energy Conversion and Management 96: 473-489.

29. A Gonzalo, L Jesus, R Miguel, M Luis, I Grzegorz (2011) Double fed induction machine-modeling and control for wind energy generation. Wiley Publication: IEEE Press Series on Power Engineering. 